\title{
Assessing the effectiveness of a social vulnerability index in predicting heterogeneity in the impacts of natural hazards: Case study of the Tropical Storm Washi flood in the Philippines
}

\section{J. Andres F. Ignacio, Grace T. Cruz, Fernando Nardi and Sabine Henry*}

\begin{abstract}
As global warming and climate change predictions become increasingly certain, there is mounting pressure to gain a better understanding of disaster risk. Climate change is seen as a major contributing factor in the recent increases in the losses and damages attributed to hazard extremes. Vulnerability is one of the key components of risk. Yet identifying who the vulnerable segments of the population are, and to which specific hazards different groups are vulnerable, remains a challenge. Measuring social vulnerability has become an active area of research, with scholars attempting to capture the differential vulnerabilities of the population exposed to certain hazards. To address these research challenges, we developed in this study social vulnerability indices at the most basic level of governance in the Philippines using raw, individual-level census data for the entire country. Our goal in conducting this research is to establish relationships between the derived vulnerability measurements and flood exposure and the impacts of coastal flash floods triggered by Tropical Storm Washi in the southern Philippines in December 2011. We find that exposure rather than vulnerability appears to play a greater role in the magnitude of the losses and damages resulting from this particular type of hazard at the localized scale.
\end{abstract}

${ }^{*}$ J. Andres F. Ignacio (corresponding author), Environmental Science for Social Change, 1/F Manila Observatory Bldg., Ateneo de Manila University Katipunan Road, Loyola Heights 1108 Quezon City, Philippines

Email: andresignacio@essc.org.ph

Grace T. Cruz, Population Institute, University of the Philippines, Quezon City, Philippines

Fernando Nardi, Università per Stranieri di Perugia, Italy

Sabine Henry, Department of Geography, University of Namur, Belgium

DOI: 10.1553/populationyearbook2015s091 


\section{Introduction}

The Hyogo Framework for Action states that "the starting point for reducing disaster risk and for promoting a culture of disaster resilience lies in the knowledge of the hazards and the physical, social, economic, and environmental vulnerabilities to disasters that most societies face, and of the ways in which hazards and vulnerabilities are changing in the short and long term, followed by action taken on the basis of that knowledge" (UNISDR 2005, p. 7). However, the promotion of resilient and adaptive societies requires a shift in focus away from natural hazards and extreme events, and toward the identification, assessment, and ranking of vulnerability (Lavell et al. 2003; Birkmann 2006a; Birkmann 2006b; IPCC 2012). Risk identification through the assessment of vulnerability can facilitate the emergence of a common understanding of responses to risk among stakeholders and actors, and thus represents one of the initial stages in the processes of risk reduction, prevention, transfer, and climate adaptation in the context of climate extremes (IPCC 2014).

Measuring vulnerability is, therefore, an increasingly important component of effective disaster risk reduction strategies (Birkmann and Wisner 2006). In the current context of more frequent disasters and mounting environmental degradation, the quantitative assessment of vulnerability is a crucial issue that the scientific community must address as they seek to provide effective strategies for creating a more sustainable and resilient world (Kasperson et al. 2001; Convertino et al. 2013).

Social assessments can illustrate the vulnerability levels of communities using quantitative evaluation algorithms, and produce indices with the goal of providing effective deterministic tools for assessing the potential impact of natural hazards on society. This fundamental approach is intended to tackle the major challenge of validating these indices with specific regard to the parameters connected to the losses and damages suffered by communities impacted by extreme hazard events. ${ }^{1}$ However, while social vulnerability indices are increasingly being developed and applied, the available data and methods for their validation remain limited (Fekete 2009).

Although the validation data needed for direct vulnerability assessment models are still lacking, indirect evaluation procedures connected to actual disaster observations and forensic studies may constitute a valid surrogate for information on the affected areas. For example, an open testing laboratory may be used to calibrate and tune vulnerability models in ex-post disaster conditions (see Birkmann and Fernando 2008). Thus, in validating the effectiveness of vulnerability indices with regard to the social impact of hazards on the exposed population, we use disaster information gathered from different and diverse sources (e.g. disaster maps, remote

1 Loss and damage refers to the adverse impacts of climate change that communities have not been able to cope with or adapt to, which include economically quantifiable and non-measurable costs (Morrissey and Oliver-Smith 2013; Warner and van der Geest 2013). 
sensing, social media). The literature reveals that several attempts have been made in the past to quantitatively map physical exposure and related risks on exposed populations.

In the work by Peduzzi et al. (2009), tropical cyclones, earthquakes, droughts, and flood hazards (accounting for 94\% of total hazards in the period 1980-2006) were evaluated with respect to population spatial distribution in order to characterize the associated physical exposure at the country scale. Using statistical tools (e.g. fitting, regression), the authors tested a total of 23 vulnerability indicators, such as the human development index, GDP per capita, and other readily available datasets. The resulting disaster risk model, which the authors validated using actual data reported from global data providers like the EM-DAT (CRED 2012), demonstrated as expected a strong correlation between vulnerability and disaster impact, especially for analyses at increasing spatial scales.

Cardona (2007) introduced a complex series of indices for the Americas designed to provide decision-makers with the ability to compare disaster risk impact with respect to management capacities across different spatial and time scales. Such studies represent a trend toward the use of index characterization and selection procedures that are strongly dependent on data specifications and availability, which are the most common and fundamental challenges for this type of research (Fekete 2009; Cardona 2007).

Explaining the complex relationships between hazards, exposure, and vulnerability by means of indirect analyses requires researchers to conduct extensive comparative investigations of several different parameters and physical and social processes in different climatic and socioeconomic conditions that compare data and results for different countries and at different time and spatial scales (Peduzzi et al. 2009). In addition, given the relatively large within-country variance in vulnerability levels and the locale-specific nature of the hazards themselves (Cutter et al. 2008), researchers need to upscale and/or downscale the disaster risk analysis to examine the specific area and conditions of exposure in relation to the different levels of vulnerability of the affected population. The literature review by Fekete (2009) showed that there were several past attempts at the sub-regional or the sub-national level to depict social vulnerability in quantitative terms, but that most of these studies lacked validation and the degree of resolution required to accurately capture the social and economic impacts on the actual communities at risk.

While obtaining proper data that provide higher levels of detail remains a major challenge, the more the spatial resolution increases, the more the available data seem to be inappropriate for evaluating levels of vulnerability. The temporal dimension is also important for periodically updating levels of vulnerability, as it can allow for a monitoring of trajectories or changes over time.

Given the importance of accurate risk evaluation and management efforts from the global to the local scale, it is crucial that decision-makers at all governance levels have detailed vulnerability information that can guide them in developing appropriate actions to strengthen community capacity and resilience to hazards under changing socioeconomic and climate conditions (IPCC 2012). 
The main goal of this paper is to evaluate the social impacts of a natural hazardi.e. coastal river flooding - using a quantitative assessment procedure that utilizes a census-based social vulnerability index $(S V I)$ developed for the Philippines at its most basic level of governance, the barangay. The proposed approach tests the relationships between social vulnerability and coastal river flood hazard $(C R F H)$ exposure using actual flood disaster loss and damage data from two case study sites. We seek to determine whether there are relationships between the risk elements of vulnerability and exposure and the negative impacts of a hazard event.

The remainder of the paper is organized as follows. In the next two sections we describe the data and the methods we use to develop and validate the SVI. We then present the results of the application of the $S V I$ estimation and validation procedure for the case study based on the loss and damage data on major floods caused by Tropical Storm (TS) Washi in mid-December 2011 in Iligan and Cagayan de Oro Cities in Mindanao in the southern Philippines. In the last section we discuss our findings and provide concluding remarks.

\section{Data}

\subsection{Data for SVI estimation}

This research is based on several datasets from a diverse set of sources. Conducting a comprehensive technical survey of barangay boundaries for the Philippines has always been a challenge because of the countless boundary conflicts between local government units at the barangay, municipal, and provincial levels (PIA 2012). Fortunately, in 2009 the Global Administrative Areas (GADM) initiative was established as part of a global effort to provide geographic bases for text-based locality descriptions and for mapping census data (GADM 2009). Although the available GIS polygon dataset for the Philippines is only indicative, it provides an overview of local governance jurisdictions at the national scale. Using these data, it is possible to identify for the purposes of conducting more in-depth analyses a collection of barangays in a municipality that normally have more accurate local boundary delineations maintained by the respective local government units.

For this study, we derived indicators of social vulnerability at the barangay level from the data fields of the raw, disaggregated 2010 Census of Population and Housing of the Philippines. The total household population of the Philippines as of 2010 was $92,097,978$ (46,458,988 males and 45,638,990 females). One-third (33.3\%) of the population were under age 15 , while $59.9 \%$ were between the ages of 15 and 59. The remaining $6.8 \%$ of the population belonged to the elderly category (aged 60 and older), as defined by Philippine law (Republic of the Philippines 1992). A total of 22,926,492 adults aged 18 and older (24.9\%) had not completed secondary education, while a total of 1,442,586 (1.6\%) individuals had disabilities. The dataset 
also included a total of 20,171,899 individual households and a total of 21,745,707 housing units.

\subsection{Validation data}

The data used for the site-specific validation were compiled by the Social Welfare and Development Offices and the Disaster Risk Reduction and Management Council Offices for both cities, as well as by the respective regional administrative offices. The data were gathered with the specific purpose of surveying the losses and damages that occurred during the Tropical Storm (TS) Washi event, which caused unprecedented flooding in the Northern Mindanao region of the Philippines in midDecember 2011. The dataset includes demographic profiles of dead and missing persons, as well as a comprehensive survey of the individuals affected by the flood in terms of injuries and damage to property. The dataset also includes a survey of housing units that were damaged to varying degrees. ${ }^{2}$ It is important to note that the level of detail of the surveyed information differed between locations, with the data for Cagayan de Oro City being less comprehensive than the data for Iligan City, particularly in terms of the demographic and geographic specifications of the individuals affected by the flood. Nevertheless, a significant amount of information is available, and the data are sufficient to allow us to perform statistical analysis on the two flooding case studies. The barangay GIS polygon data provided by the Planning and Development Offices of the two cities give more accurate information on the barangay boundaries maintained by the local government than the publicly available GADM dataset.

\section{SVI estimation method and results}

In this section we describe the method used to develop the social vulnerability index derived from the presented disaggregated census data. The empirical measurements of social vulnerability combine a number of indicators that can be used to obtain characteristics or parameters that describe a social system's state of vulnerability (Cutter et al. 2008). The SVI for the Philippines presented here is based on the 2010 Census of Population and Housing, with the barangays being used as the basic unit of analysis, and three types of information being provided per barangay: i.e. individual members, households within the barangay, and housing units aggregated at the barangay level (Ignacio and Henry 2013a). Because we have access to disaggregated or raw data for both population and housing characteristics, we are able to combine the social and the housing-based indicators in developing an SVI

2 The database identifies three degrees of flood damage to housing units: 1) inundation, or flooding without damage to the housing structure; 2) partial damage, or minor damages sustained by the housing unit; and 3) total damage, or damage that renders the housing unit irreparable. 
that spans all 42,020 of the populated barangays in the Philippines. Barangay aggregations are the best way of locating census data at the most detailed unit possible, which is critical for identifying the populations exposed to particular hazards. Although the barangay boundaries used for the nationwide mapping are arbitrary, the boundaries used in the case study sites have an acceptable level of accuracy, as they have been provided by the respective city governments. In this research we focus on a discrete geographical level of aggregation (the barangay) in assessing the site-specific impacts of flood hazard on a population, and thus minimize the problems associated with the modifiable areal unit problem (MAUP) detailed by Openshaw (1983).

The SVI scores are estimated at the national level as percentile scores. For the case study sites, geographic subsets of the SVI for the barangays comprising Iligan and Cagayan de Oro Cities are extracted from the national database to allow us to perform a more detailed analysis of the SVI vis-à-vis hazard impacts on the population at the local scale. The indices are measured separately using corresponding indicators that are based on the pertinent census fields (see Appendix B for the complete list of census fields).

Utilizing the relevant fields provided by the 2010 raw census data, 18 indicators were derived (Table 1) and simple additive indices or composite indicators based on individuals, households, and housing characteristics were developed and computed for the barangays. Many of these indicators were selected based on groups generally known to have high levels of vulnerability, as illustrated in Cutter et al. (2003: pp. 246-249). Our social vulnerability concepts were derived based on the existing literature, and on whether they could be measured from the available census fields.

Demographic groups such as the very young, the very old, the disabled, singleparent households, and low-income earners are thus seen as vulnerable (King and MacGregor 2000). Because the legal working age is 15 in the Philippines, the dependent age range is defined as ages 0-14 (Racelis and Salas 2008). People aged 60 and older are classified as senior citizens (Republic of the Philippines 1992). Following the work of Cutter et al. (2003), the additional indicators we considered are average household size, low adult educational attainment (no secondary school diploma), the share of females, and the percentage of households headed by women. An additional variable, the proportion of females aged 20-39 who had a secondary education or higher, was included following the work of Streissnig et al. (2013), who found that this variable has a positive relationship with vulnerability reduction. Lutz et al. (2008) showed that the proportion of younger women who have a junior secondary or higher education is important in social and economic development, as these women play key roles in family matters ranging from child-rearing to family health, household decision-making, and changes in labor force participation. ${ }^{3}$

\footnotetext{
3 According to the Philippine Commission on Women (2014), women have higher functional literacy rates than men, and have a relatively high labor force participation (49.8\% in 2013).
} 


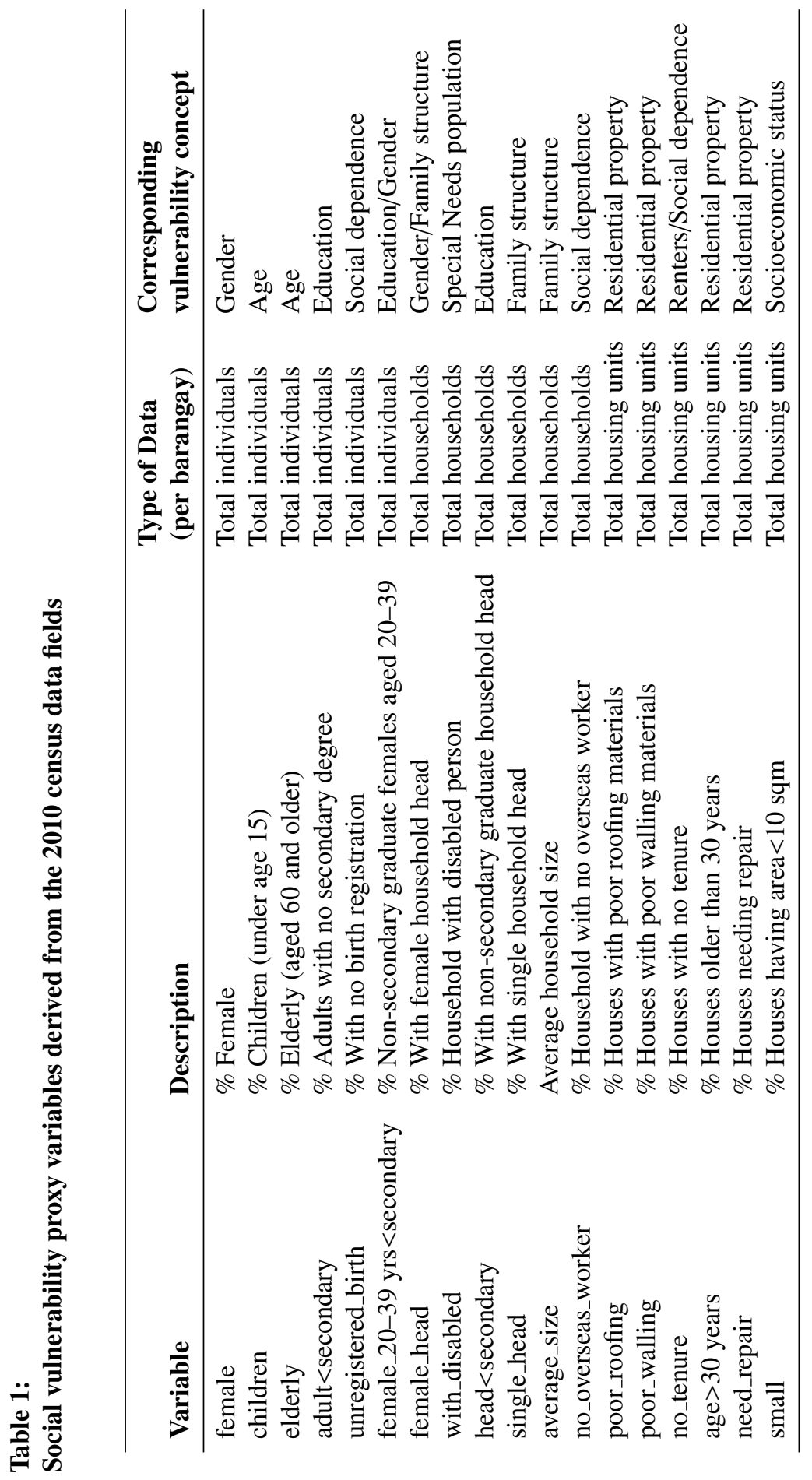


Other vulnerability proxies based on Cutter's work were derived from the housing database: e.g. poor roofing materials, poor walling materials, lack of tenure, needing repairs, old structures, and small house floor area. Finally, since the raw database is in a disaggregated form, other combinations of variables linked to social vulnerability are evaluated: households in which the adults lack high school diplomas and households that receive no support from overseas foreign workers. More than $10 \%$ of the population of the Philippines are working abroad (Commission on Filipinos Overseas 2010), and these overseas workers provide significant resources to their families in the form of remittances.

An index can be simply constructed as an additive combination of several indicators, assuming that all of the components reflect the underlying construct equally (Carmines and Woods 2003). As indices attempt to condense a complex reality into simple terms, they can serve as good measures (Diener and Suh 1997). There are, however, limitations to composite indices, as they do not indicate the structure or the causes of the vulnerabilities, and they do not specify the degree to which each individual indicator affected the overall outcome (Adger et al. 2004). Weighting schemes for indicators have been suggested based on a number of approaches and techniques, such as expert opinion and principal components analysis (Nardo et al. 2005; Cutter et al. 2003; Rygel et al. 2006). Although there is a general consensus regarding the overall factors that influence social vulnerability to natural hazards, scientists and professionals tend to disagree on the selection of specific indicators and on weighting schemes (Gall 2007). Given these limitations and for the sake of simplicity, an approach of an equal weighting of indicators was adopted.

The selected indicators for $S V I$ are combined into three equally weighted indices per data type:

$$
\begin{aligned}
& S V I_{\mathrm{in}}=\frac{\left(I_{\mathrm{in}}^{1}+I_{\mathrm{in}}^{2}+\cdots+I_{\mathrm{in}}^{i}\right)}{i} \\
& S V I_{\mathrm{hh}}=\frac{\left(I_{\mathrm{hh}}^{1}+I_{\mathrm{hh}}^{2}+\cdots+I_{\mathrm{hh}}^{i}\right)}{i} \\
& S V I_{\mathrm{hs}}=\frac{\left(I_{\mathrm{hs}}^{1}+I_{\mathrm{hs}}^{2}+\cdots+I_{\mathrm{hs}}^{i}\right)}{i}
\end{aligned}
$$

where $S V I_{\mathrm{in}}, S V I_{\mathrm{hh}}$ and $S V I_{\mathrm{hs}}$ correspond to the individual, the household and the housing unit social vulnerability indices respectively; while $I_{\mathrm{in}}^{i}, I_{\mathrm{hh}}^{i}$, and $I_{\mathrm{hs}}^{i}$ correspond to the individual, the household and the housing indicators respectively. A total of six indicators per data type are derived to compute the respective composite SVIs per barangay. As most of the values of the individual indicators are represented as percentages that correspond directly to increasing levels of vulnerability, the average household size indicators are normalized based on the maxima and minima of the entire dataset at the national level for consistency.

Figures 1 to 3 map the different $S V I$ results, which show quintiles ranging from very high to very low $S V I$ types for a sample geographical area covering Iligan and 
Cagayan de Oro Cities in Northern Mindanao. The quintile ranges used are based on the entire national dataset and illustrate the states of measured vulnerability in these areas compared to the national values. It is worth noting that barangays farther from the city centers tend to have higher relative $S V I$ values.

\section{Defining zones of flood exposure}

In its Fifth Assessment Report, the IPCC defines disaster risk as the convergence and interplay of hazard, vulnerability, and exposure (Field et al. 2014). As in this paper we seek to evaluate the impacts of a natural hazard in terms of the measurable factors associated with risk (i.e. vulnerability), measuring the level of exposure to a hazard can help determine whether this risk factor has greater significance in determining the level of vulnerability in the overall outcome of the TS Washi flood disaster.

As we mentioned above, the Planning and Development Offices of Iligan and Cagayan de Oro Cities provided geographic information system (GIS) data that show the barangay boundaries more accurately. The data for the domain on the TS Washi flood-affected areas were provided by the Planning and Development Office of Iligan City, while the data for the Cagayan de Oro City flood zones were provided by the Xavier University Engineering Resource Center (2011). Both datasets were based on ground surveys of the extent of flood damage. Additional geospatial data on features such as elevations and rivers were taken from standard topographic maps at a 1:50,000 scale published by the National Mapping Resource Information Authority (NAMRIA) of the Philippine government. In addition, global-scale data were gathered, including digital elevation models (DEMs) produced by the Shuttle Radar Topography Mission (SRTM) (Farr et al. 2007) and aerial photographs and satellite imagery from national and international geospatial data providers. This diverse and heterogeneous set of geospatial information was processed to develop a robust and homogeneous GIS database that provides an a priori representation of the areas exposed to flood hazards, along with the social and demographic characteristics of these areas based on the census data.

In the case of the TS Washi disaster, flash floods were the main reason for the loss of life and the destruction of property. In order to delineate flash flood hazard exposure zones, the simple model developed by Ignacio and Henry (2013b) was considered and adapted. A combination of two basic geomorphic parameters extracted from the SRTM DEM define the primary areas of $C R F H$, which is a function of elevation from the coast and slope:

$$
C R F H=E_{10 m} \cap S_{2 \%}
$$

where $E_{10 m}$ and $S_{2 \%}$ are the coastal areas with, respectively, an elevation lower and equal to 10 m.a.s.l. and slope gradients of $2 \%$ or lower. Note that the original elevation threshold of $5 \mathrm{~m}$ defined by Ignacio and Henry has been increased to effectively represent the TS Washi flooded zones. The $C R F H$, measured in 
Figure 1:

$S V I_{\text {in }}$ distribution in Iligan and Cagayan de Oro Cities

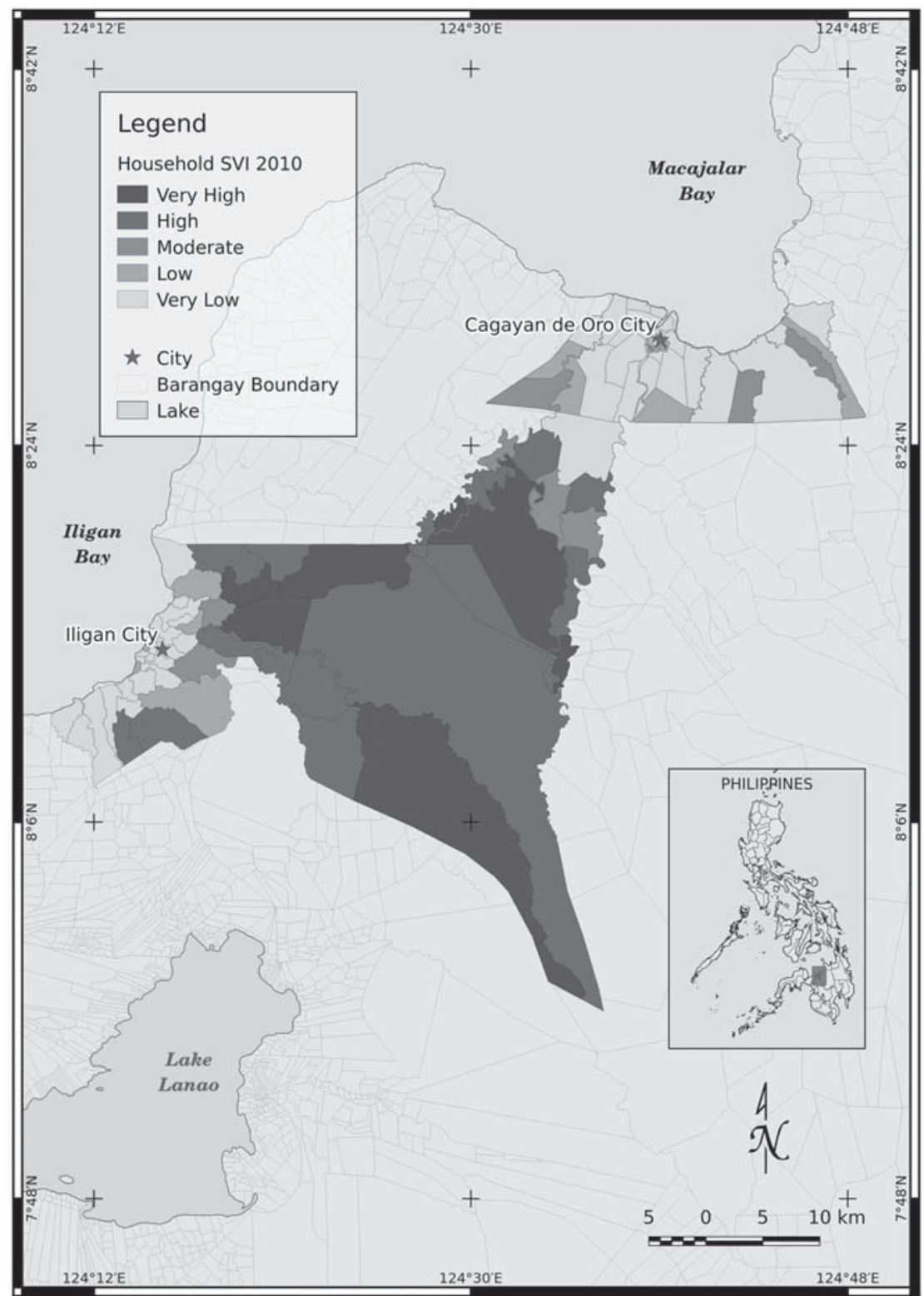

Source: Compiled by the author. 
Figure 2:

$S V I_{\mathrm{hh}}$ distribution in Iligan and Cagayan de Oro Cities

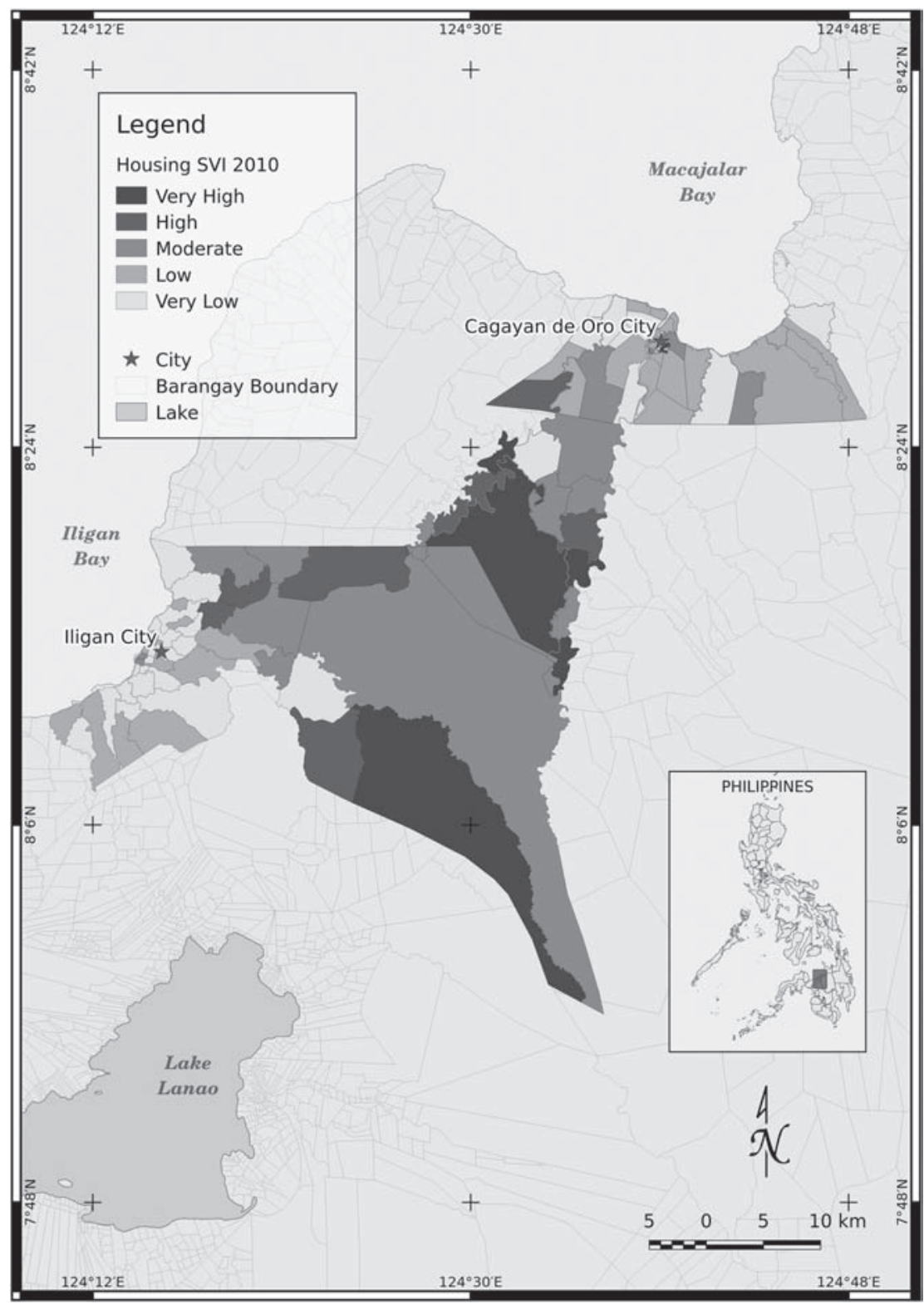

Source: Compiled by the author. 
Figure 3:

$S V I_{\text {hs }}$ distribution in Iligan and Cagayan de Oro Cities

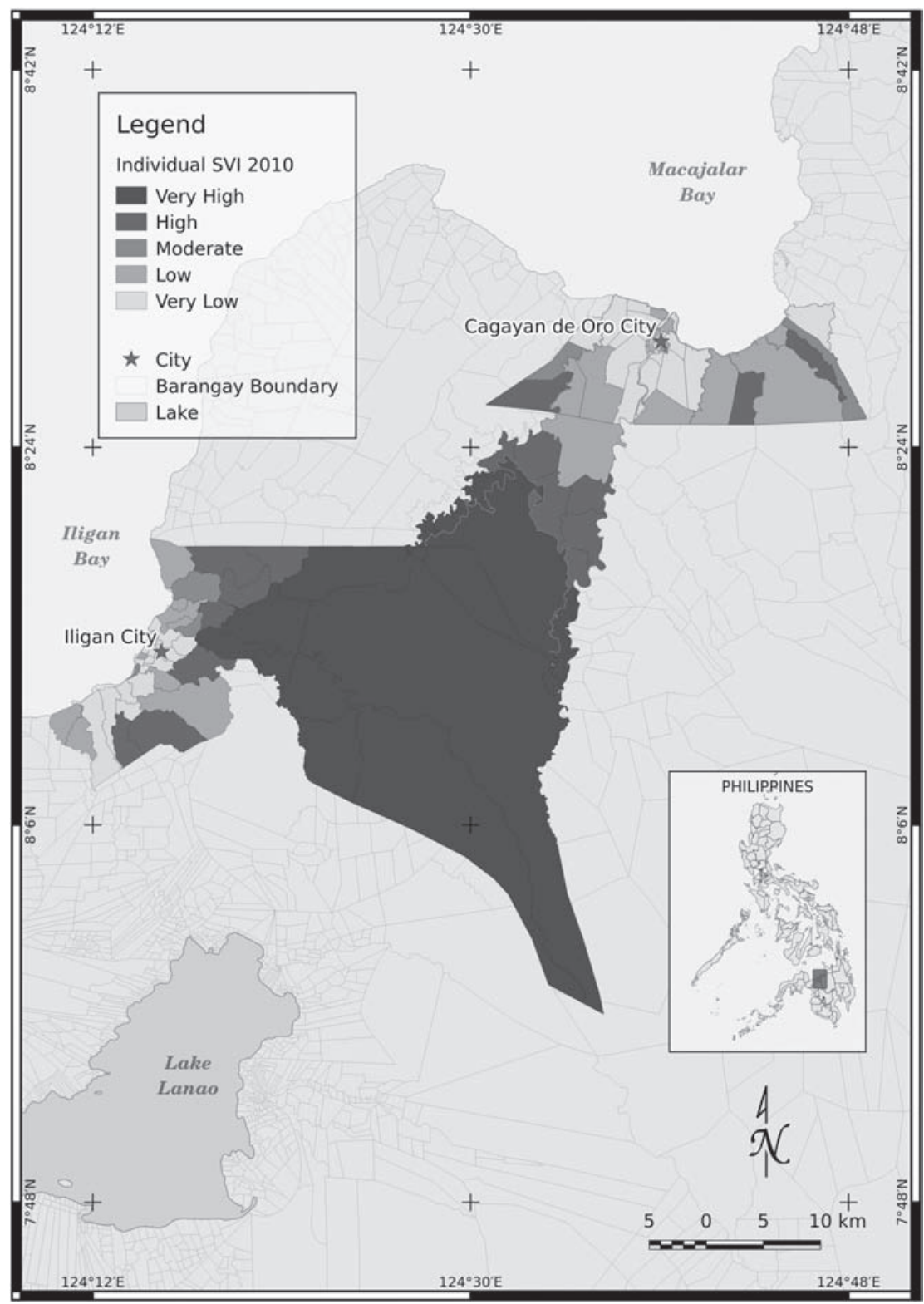

Source: Compiled by the author. 
hectares, is a simple attempt at delineating the flood plain areas of the coast-draining rivers with flash flood potential using the best available data. The CRFH zones are then used to identify the flood-prone barangays using standard GIS overlay tools. We considered using more complex terrain analysis for flood plain mapping (Nardi et al. 2006; Nardi et al. 2013; Manfreda et al. 2014), and developing and applying a spatially distributed, physically based hydrologic and geomorphic flood plain delineation approach (Grimaldi et al. 2004; Grimaldi et al. 2012; Grimaldi et al. 2013). But for the hydrogeomorphic setting of the coastal areas of Northern Mindanao in the southern Philippines, we selected a simple approach based on the geometric parameters of differential elevation and slope, as this approach seems to be the most efficient way of identifying low-lying river bottoms and potentially flooded zones given the flat nature of the domain of interest (Nardi et al. 2008).

\section{Case studies: Iligan and Cagayan de Oro and the TS Washi flood}

Iligan and Cagayan de Oro Cities are selected as case studies (Figure 4). Iligan City is located in the Northern Mindanao region of the Philippines. It includes 44 barangays or villages with a total area of $813.37 \mathrm{~km}^{2}$ and a household population of 321,156; as of May 2010. Three major river systems - the Mandulog, the Tubod, and the Lanao - flow through the coastal barangays before emptying into Iligan Bay. Cagayan de Oro City is located northeast of Iligan City, and is also on the coast of Northern Mindanao. It has 80 barangays with a total area of $488.9 \mathrm{~km}^{2}$ and a household population of 598,803; as of May 2010. Two major rivers flow through the western portion of Cagayan de Oro City: the Iponan and the Cagayan. These rivers and a series of smaller coastal watersheds all drain into Macajalar Bay.

On December 16, 2012, TS Washi passed through Northern Mindanao, an area that is rarely hit by typhoons. Precipitation of $180.9 \mathrm{~mm}$ accumulated in 24 hours, making this an event with a return period of once in 75 years (RDC-X 2012). Flash floods affected several communities along the coast of Northern Mindanao, with the densely populated urban centers of Iligan and Cagayan de Oro Cities reporting the highest rates of loss and damage.

According to the Northern Mindanao Regional Disaster Risk Reduction and Management Office (DRRMO) of the Philippine government, in Iligan City alone 148 people died and 1,023 people went missing. A total of 94,611 individuals were affected, given the population specifications within the flood hazard zone of the Mandulog and Tubod river systems. The flood totally destroyed 4,448 housing units and partially destroyed 5,884 housing units, while a total of 10,582 houses were hit by the flood waters. For Cagayan de Oro City, the official data show that 569 people died and 363 people went missing. A total of 47,526 individuals living within the flood hazard areas of the larger Cagayan river were significantly affected. The flood totally destroyed 3,998 houses and partially destroyed 6,162 houses, and a further 
Figure 4:

Barangays and Watersheds of Iligan and Cagayan de Oro Cities

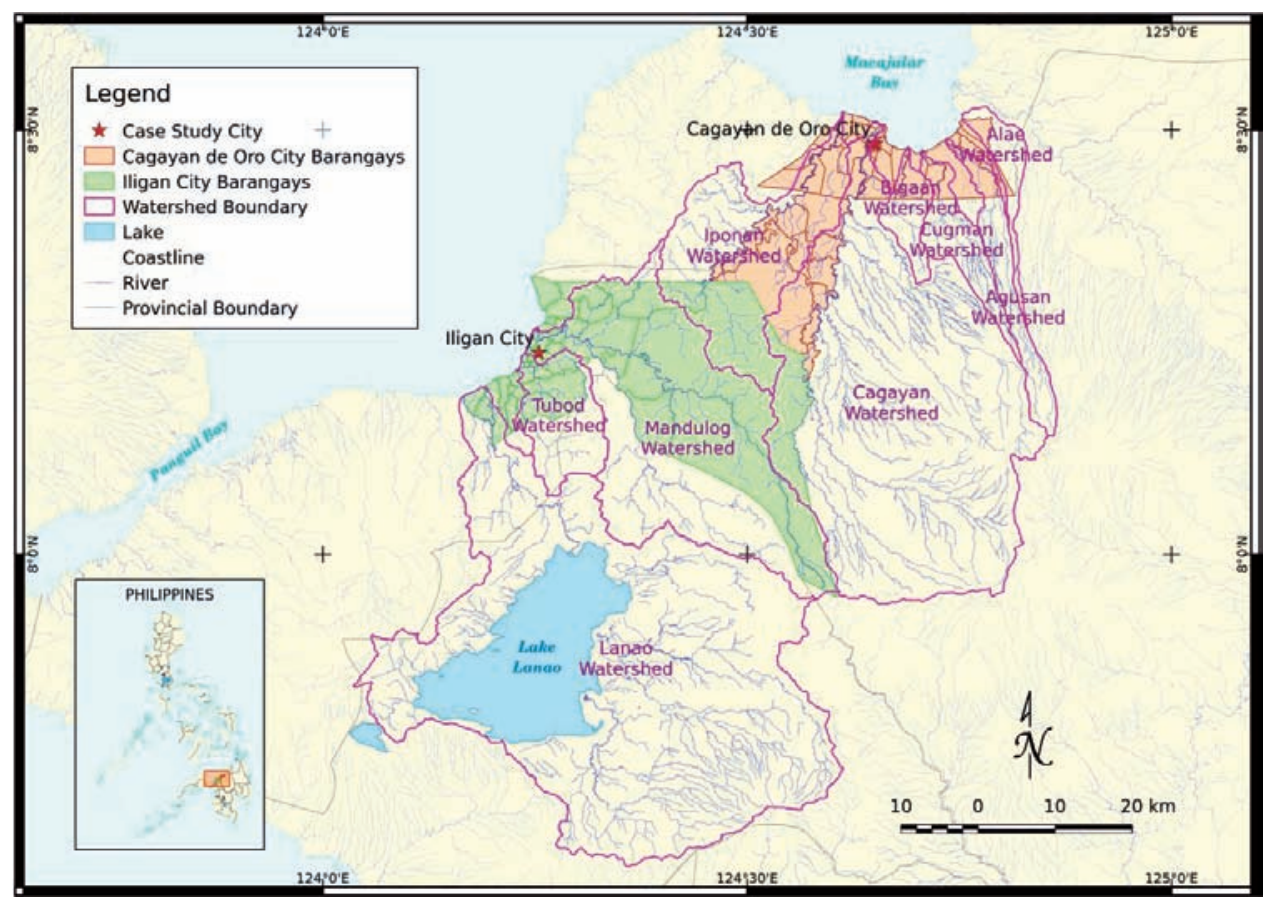

Source: Philippine National Mapping Resource Information Authority (NAMRIA) 1:50,000 topographical maps; Iligan and Cagayan de Oro City Planning and Development Offices; Environmental Science for Social Change; and www.gadm.org (compiled by the author).

2,981 houses were inundated with no significant damage reported. A full report of the TS Washi impact on the two case study areas can be found in Appendix A.

\section{Results}

\subsection{Regression analysis for the determinants of the flood impact}

For a comprehensive and homogeneous representation of the flood social impacts, a multiple regression analysis is implemented using the $S V I$ variables and the coastal risk flood hazard $(C R F H)$ as predictors. The multiple linear regression model is defined as follows:

$$
y_{j}=\alpha+\sum_{k} \beta_{k} x_{k}+\epsilon
$$


Table 2:

Correlation matrix of predictor variables for Iligan City

\begin{tabular}{lllll}
\hline & $\boldsymbol{S V} \boldsymbol{I}_{\text {in }}$ & $\boldsymbol{S V} \boldsymbol{I}_{\mathrm{hh}}$ & $\boldsymbol{S V} \boldsymbol{I}_{\mathrm{hs}}$ & $\mathbf{C R F H}$ \\
\hline$S V I_{\text {in }}$ & 1.000 & & & \\
$S V I_{\mathrm{hh}}$ & 0.843 & 1.000 & & \\
$S V I_{\mathrm{hs}}$ & 0.850 & 0.856 & 1.000 & \\
$C R F H$ & -0.399 & -0.417 & -0.395 & 1.000 \\
\hline
\end{tabular}

where $y_{j}$ represents the three outcomes of interest: i.e. (1) number of dead + missing; (2) number of affected individuals; and (3) levels of damage to housing units; and $x_{k}$ represents the various predictors $\left(S V I_{\mathrm{in}}, S V I_{\mathrm{hh}}, S V I_{\mathrm{hs}}\right.$, and $\left.C R F H\right)$.

Table 2 displays the Pearson's R correlation matrix among the different predictors for Iligan City, which shows that $S V I_{\mathrm{hs}}$ is highly correlated with $S V I_{\mathrm{hh}}$ and $S V I_{\mathrm{in}}$ with 0.856 and 0.850 correlation values respectively. Even if the principle of multicollinearity applies here, the different $S V I$ variables are not combined to describe the single $S V I$ outcomes for independently evaluating the different aspects of vulnerability at the individual, the household, and the housing level.

As a result of the high correlations, several ordinary least square (OLS) simple regression models are used for each variable individually in the form:

$$
y=\alpha+\beta x+\epsilon
$$

where $y$ represents the outcome variables and $x$ represents the different $S V I$, as well as the $C R F H$ predictors. Since the purpose of this analysis is to establish whether there is a predictive relationship between the $S V I$ or the $C R F H$ and the outcomes resulting from the hazard event, and because the SVI is a continuous variable, the OLS simple regression can establish whether there are relationships between the assumed predictors and the outcomes.

\subsection{SVI for Iligan and Cagayan de Oro cities}

Table 3 presents a statistical summary of the three SVI composite variables for Iligan and Cagayan de Oro Cities, respectively, based on the 2010 census fields. As the resulting scores are based on the percentages of individuals, households, or housing units per barangay (except for the average household size indicator), the results are comparable at the barangay level for each single SVI. The summary statistics show relatively similar average and median values for the two cities. The index scores for each barangay served as input predictor variables in the regression models, which will be discussed in detail below.

Figure 5 shows the extent of flood damage to the barangays, as delineated by the Iligan City Planning Office after the disaster. The destructive flooding region, 
Table 3:

Summary statistics of the SVI scores for the barangays of Iligan and Cagayan de Oro Cities

\begin{tabular}{llllllcl}
\hline City & Variable & $\boldsymbol{n}$ & mean & sd & median & min & max \\
\hline Iligan & $S V I_{\text {in }}$ & 44 & 26.50 & 9.84 & 22.41 & 16.65 & 55.69 \\
Iligan & $S V I_{\mathrm{hh}}$ & 44 & 36.10 & 3.74 & 34.52 & 30.40 & 42.71 \\
Iligan & $S V I_{\mathrm{hs}}$ & 44 & 18.67 & 7.44 & 16.78 & 8.15 & 40.21 \\
Cagayan de Oro & $S V I_{\mathrm{in}}$ & 80 & 21.45 & 5.7 & 20.18 & 10.42 & 39.23 \\
Cagayan de Oro & $S V I_{\mathrm{hh}}$ & 80 & 35.01 & 3.44 & 34.65 & 25.4 & 44.02 \\
Cagayan de Oro & $S V I_{\mathrm{hs}}$ & 80 & 19.02 & 9.09 & 17.32 & 5.32 & 61.49 \\
\hline
\end{tabular}

Figure 5:

Flood zones and CRFH areas along the Mandulog and the Tubod rivers in Iligan City

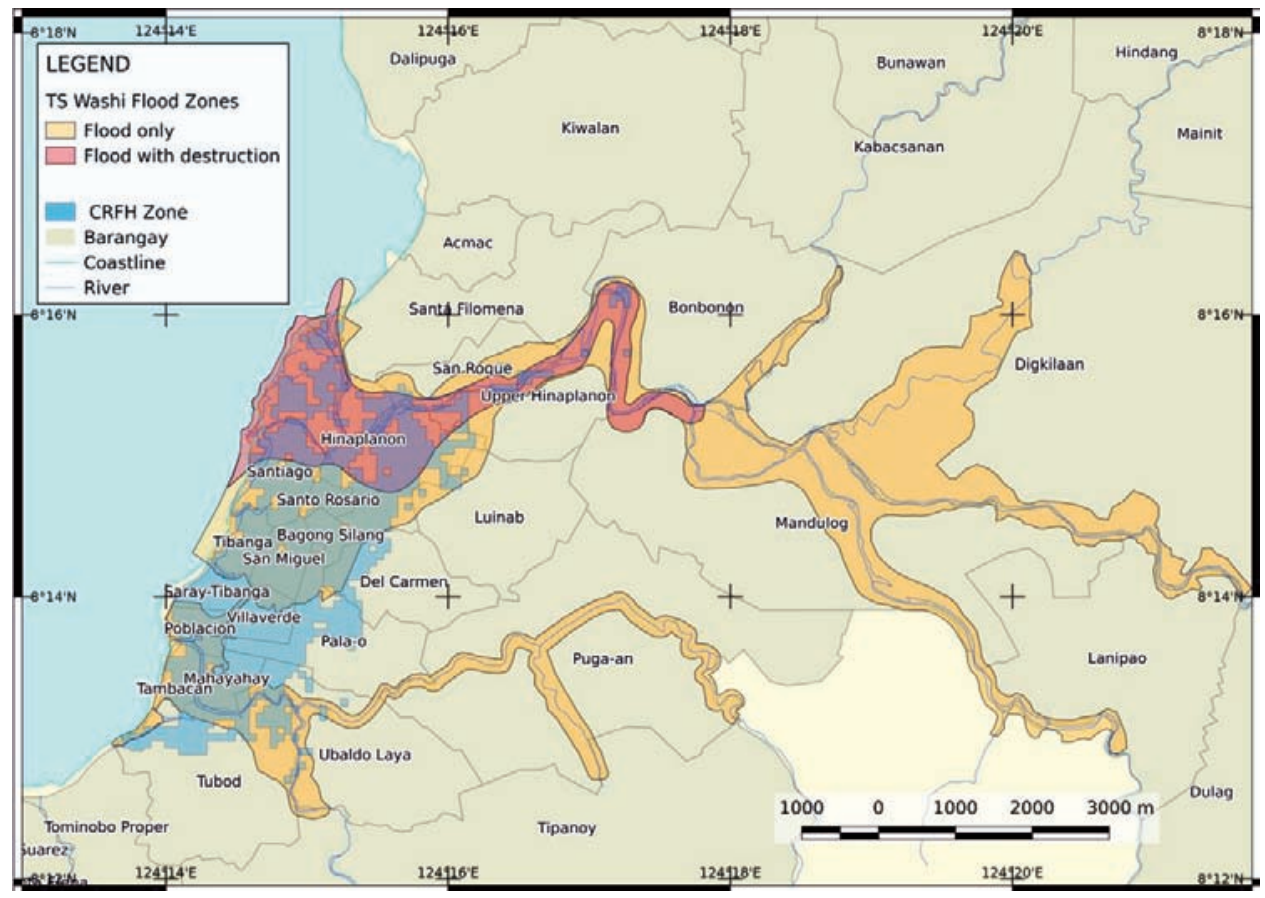

Source: Iligan City Planning and Development Office; NAMRIA 1:50,000 Topographic Maps (compiled by the author). 
shown in red, is specifically located along the Mandulog flood plain in the north of the region, while the inundated zones with non-destructive conditions depicted in an orange color are mainly distributed along the Mandulog and Tubod river channels. The $C R F H$ areas shown in a semi-transparent blue color have a significant spatial correlation with the flooded zones. Since the $C R F H$ areas are provided a priori using the available observation data, this information is used as a predictor variable in the linear regression model to allow us to compare its influence on the outcomes of the flood impact, as expressed in terms of the losses and damages incurred.

The $C R F H$ areas within the watersheds of the Mandulog and the Tubod rivers measured 883 hectares. The Hinaplanon barangay had the largest share of these areas, with 182 hectares (20.6\%); followed by Palao, with 84 hectares $(9.5 \%)$; and Santiago, with 80 hectares $(9.1 \%)$. The $C R F H$ areas included 20 barangays that experienced flooding during TS Washi. Only five barangays that were flooded were not associated with the $C R F H$ areas, as they were located relatively far away from the river outlets. The same analysis was conducted for Cagayan de Oro City, but it is not included in this section for the sake of brevity.

\subsection{Flood impact with respect to social vulnerability and exposure}

The $S V I$ and the $C R F H$ variables are represented using the selected OLS regression model. As the numbers of samples are limited for the two sites, the distribution of the raw output data is highly skewed, but the application of the log function for interpolating the social impact behavior as a function of the driving force of the flooding scenario provides a comprehensive linear relationship between the predictors and the outcomes; as we can see in Figures 6, 7, and 8. Figure 6 graphically represents the log function results in comparison with the different variable plot pairs of the raw data with respect to the outcomes of the dead + missing people and the affected people for the two sites.

Figure 7 presents $S V I_{\mathrm{hs}}$ with respect to the different housing damage types, comparing the raw and the log-treated outcomes. Figure 8 presents the $C R F H$ area with respect to the different housing damage types and their logs, which shows a consistent improvement in the relationships between the variable pairs. This justifies the use of OLS regression models to characterize the relationship between the predictors and the outcomes.

Table 4 shows the results of the simple OLS linear regressions of the log values of the outcomes on the predictor variables for each of the case study sites. The regressions of the dead and missing outcome on the predictors do not seem to exhibit statistically significant results, but this is expected considering the low number of dead and missing victims per barangay. But for the affected people the statistical significance of the regression estimates is strong. This finding is supported by the more comprehensive loss and damage data that were gathered from the individuals affected by the disaster (see Appendix A). Moreover, the number of affected individuals per barangay is much higher with respect to the numbers of dead 
Figure 6:

Comparison of scatterplots of SVI and CRFH vs. raw and log of dead + missing and affected showing the corresponding regression line and confidence regions in Iligan and Cagayan de Oro Cities
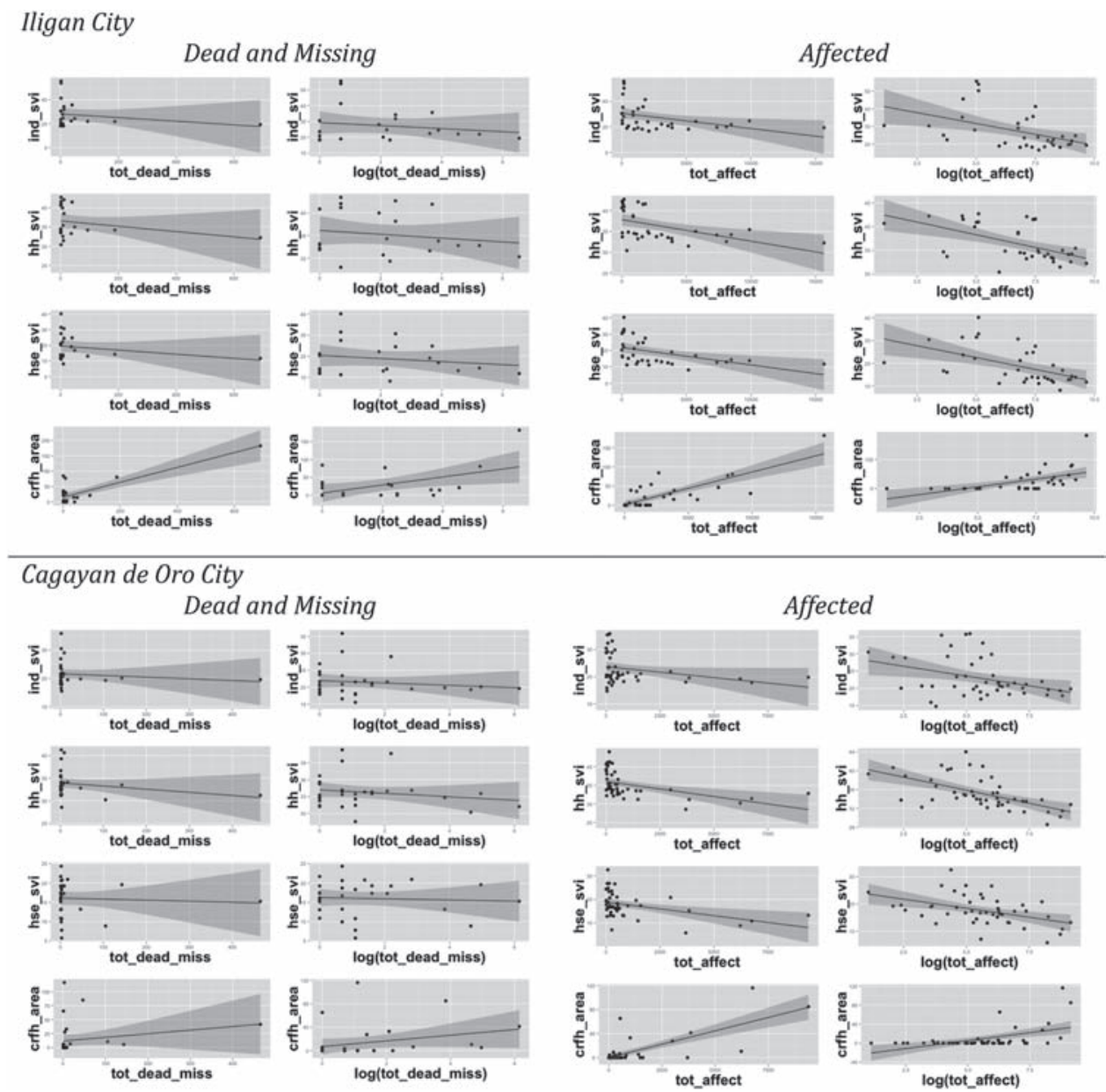

Source: Compiled by the author.

and missing for both case study sites (see Appendix A Tables A.1 and A.3). The regression of flood damage types on $S V I_{\mathrm{hs}}$ and $C R F H$ reveal strong relationships as well particularly for the partially damaged house category. $S V I_{\mathrm{hs}}$ is also strongly linked with the flooded house variable for Iligan City, but there do not seem to be enough cases in Cagayan de Oro City $(n=10)$ to statistically characterize the connection. 
Figure 7:

Comparison of scatterplots of $S V I_{\mathrm{hs}}$ vs. raw and log of housing damage types showing the corresponding regression line and confidence regions in Iligan and Cagayan de Oro Cities
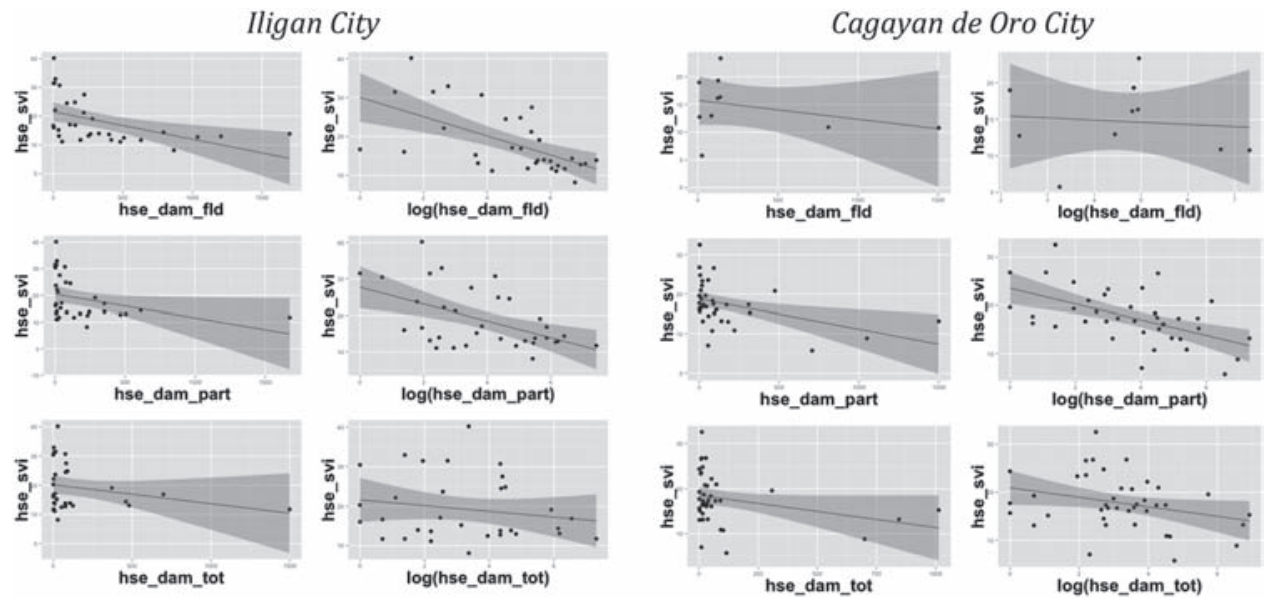

Source: Compiled by the author.

\section{Figure 8:}

Comparison of scatterplots of $\mathrm{CRFH}$ vs. raw and log of housing damage types showing the corresponding regression line and confidence regions in Iligan and Cagayan de Oro Cities

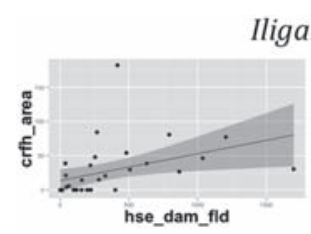

Iligan City
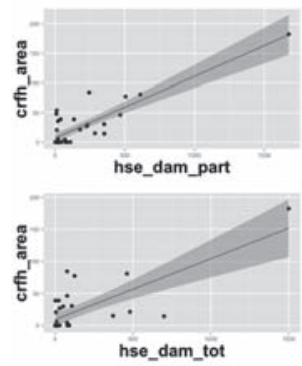
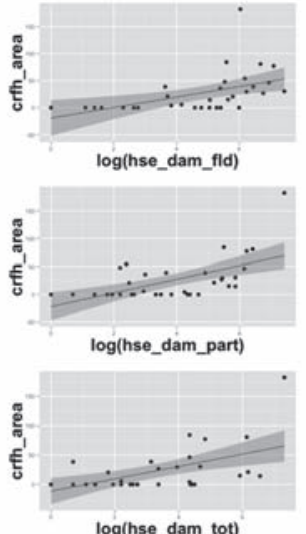

Cagayan de Oro City

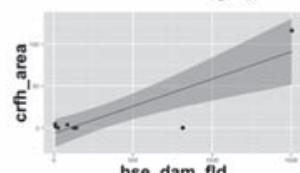

hse_dam_fild

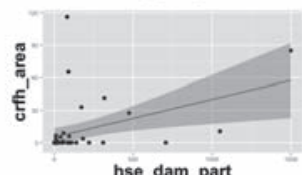

hse_dam_part

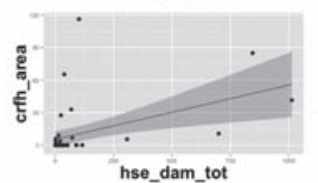

log(hse_dam_fld)

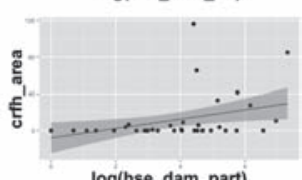

log(hse_dam_part)

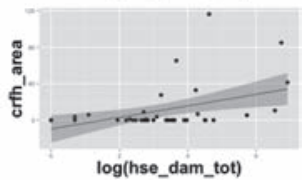

Source: Compiled by the author. 
Table 4:

Simple regression results of loss and damage vs. vulnerability and exposure. Numbers in parentheses are standard errors

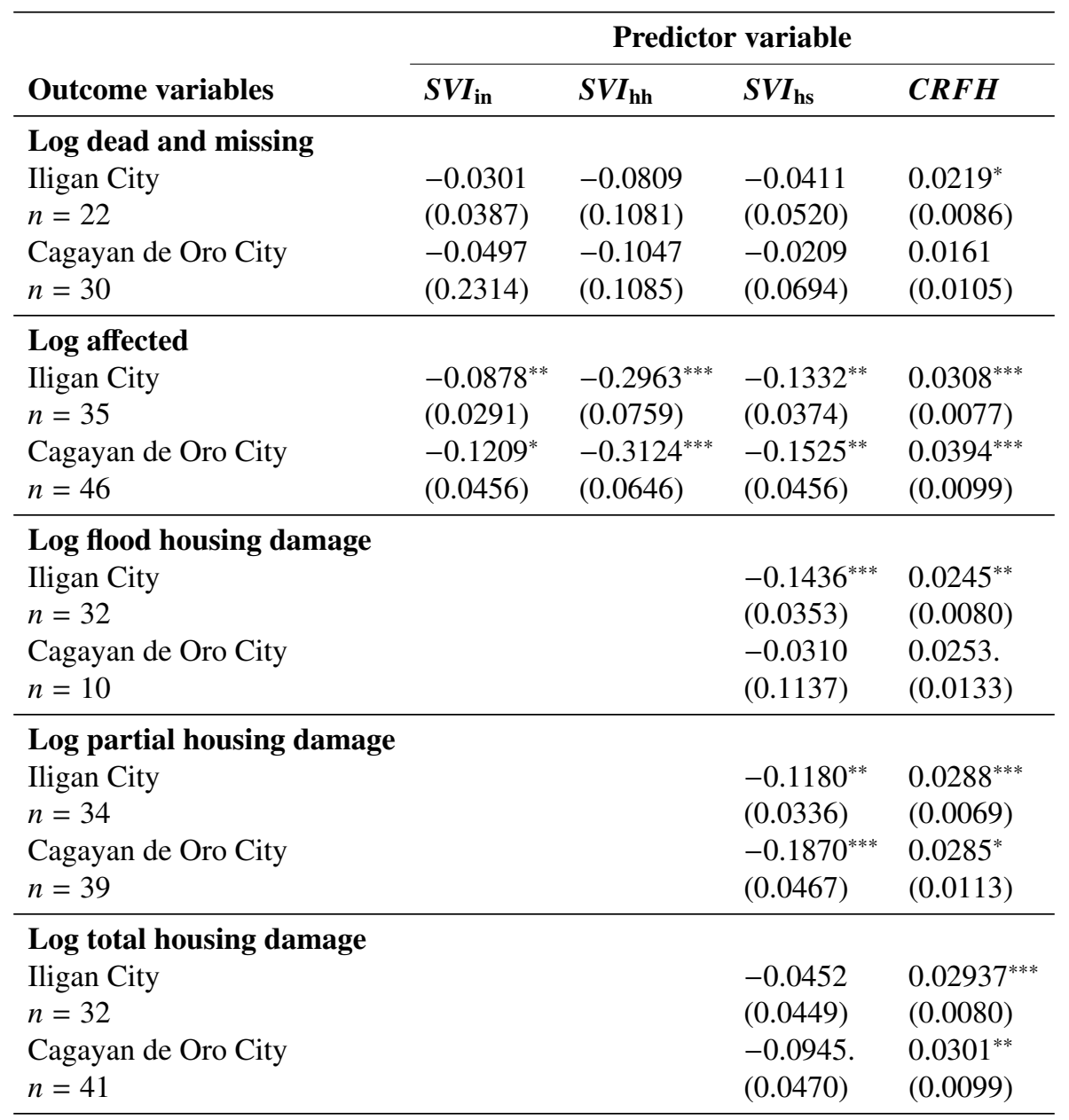

Note: Significance codes: $0={ }^{\text {**** }} ; 0.001={ }^{(* *}, ; 0.01={ }^{{ }^{*},} ; 0.05=$ '?

In terms of the relationships between the variable pairs in the regression models, Table 4 consistently shows inverse relationships between the three composite SVI variables and the outcomes. These relationships are graphically represented in the scatterplots of Figures 6, 7, and 8, which show the negative slopes of the regression lines. These results reveal an unexpected trend with respect to the direct relationships between social vulnerability and the magnitude of losses and damages, particularly in the regression of affected individuals and partial housing damage. This rather surprising finding is unlikely to be due to poor data quality, since the 
data on the affected individuals and the types of housing damage are usually reliable, given the more consistent survey information provided by the survivors and by the post-disaster observations of damage to the housing units.

In order to further investigate which factor in the SVI contributes to the results shown in Table 4, a further set of regression analyses is presented on the decomposed $S V I$ variables; i.e. on the six individual indicators that comprise each of the SVIS (see Table 1). Table 5 provides the summary of the results using the procedure that was implemented for the overall SVI indices. The outputs confirm these trends, thus validating the regression model behavior for the dead and missing outcomes with no statistically significant relationship between the variable pairs - except for the no_tenure 4 variable for Iligan City, which also has a relatively high standard error. It is worth noting that education-related regressors (i.e. female_20-39yrs $<$ secondary ${ }^{5}$ and head $<$ secondary ${ }^{6}$ ) for the affected population outcomes show a consistent dependency link between the two case studies. The poor_walling ${ }^{7}$ indicator variable for $S V I_{\mathrm{hs}}$ also exhibits a consistent degree of significance in many of the outcomes. The no_overseas_worker ${ }^{8}$ variable is also significant and consistent between the two sites. However, in line with the pattern presented in Table 4, the relationships for all the mentioned regressors are also consistently inverse in relation to the log of the outcomes.

A final series of models is formulated and applied that combine the component variables for each of the SVIs as regressors in a multiple linear regression model, defined by the equation:

$$
\log y_{j}=\alpha+\sum_{m} \beta_{m} x_{m}+\epsilon
$$

where $\log y_{j}$ represents the $\log$ of the outcomes (i.e. number of dead + missing, affected individuals, and levels of damage to housing units), and $x_{m}$ represents the various indicators for each of the SVI variables, as listed in Table 1. The purpose of this last test is to check for the simultaneous influence of the decomposed $S V I$ variables on the log of the outcomes, and to determine which variable has the most impact.

Table 6 lists the results of the multiple linear regressions of the $\log$ of the outcomes on the decomposed variables. The results are not as expected. We find that for the two case study sites the head $<$ secondary ${ }^{9}$ and poor_walling ${ }^{10}$ variables are significantly consistent for the affected population outcome. These two variables

\footnotetext{
$4 \%$ of houses with no tenure.

$5 \%$ of women aged 20-39 who were not high school graduates.

$6 \%$ with a non-high school graduate household head.

$\%$ of houses with poor walling materials.

$8 \%$ of households with no overseas worker support.

$9 \%$ with a non-secondary graduate household head.

$10 \%$ of houses with poor walling materials.
} 


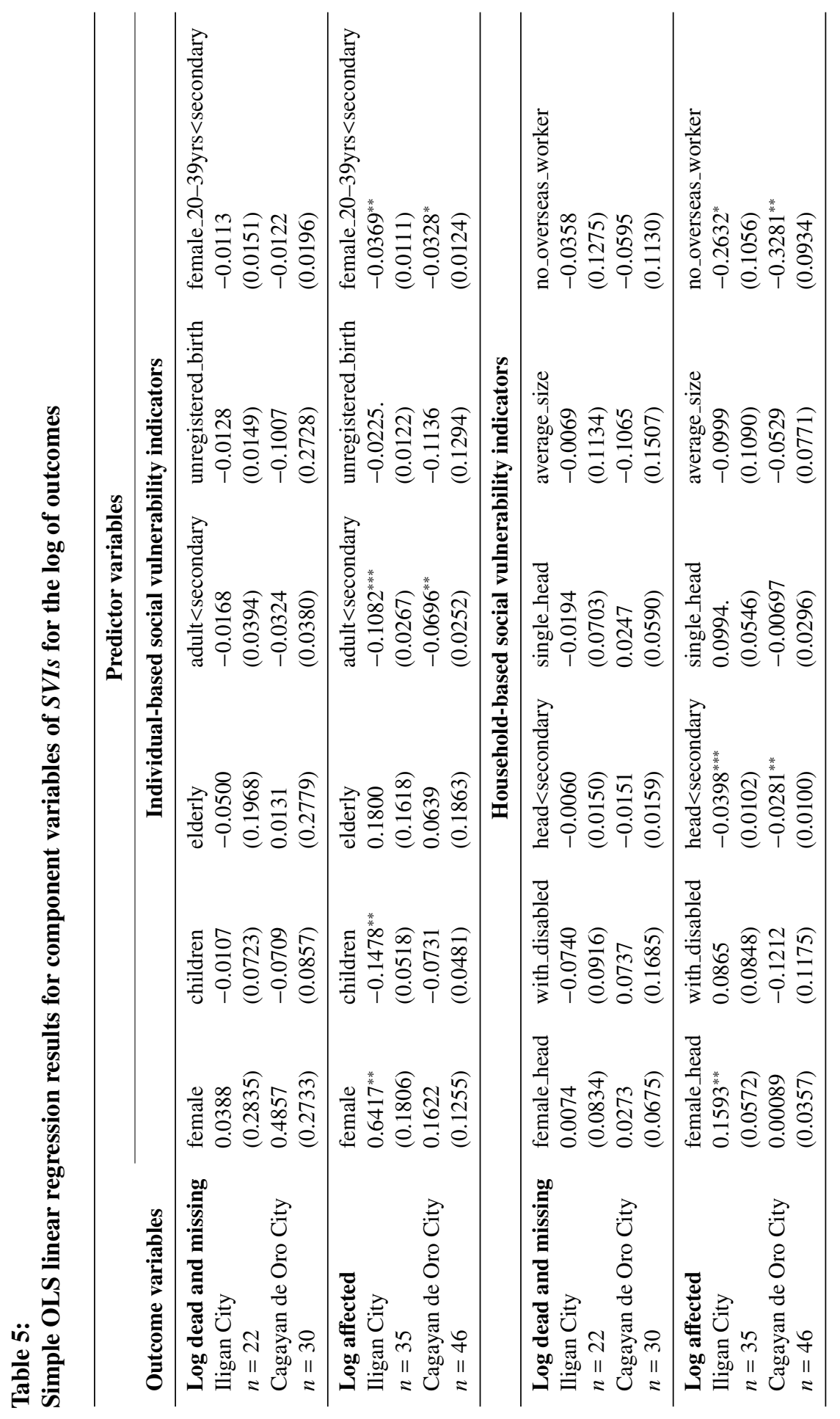




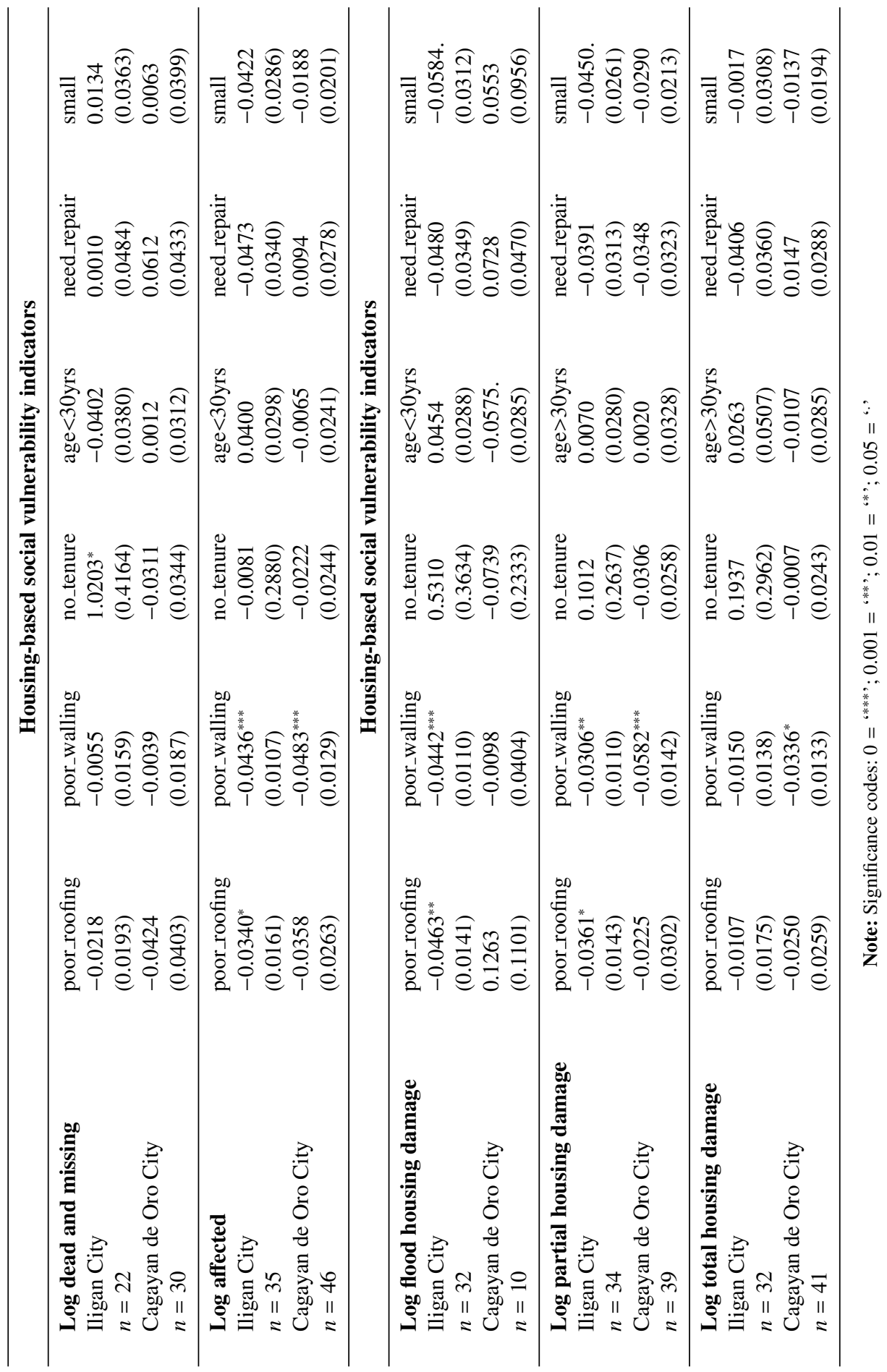




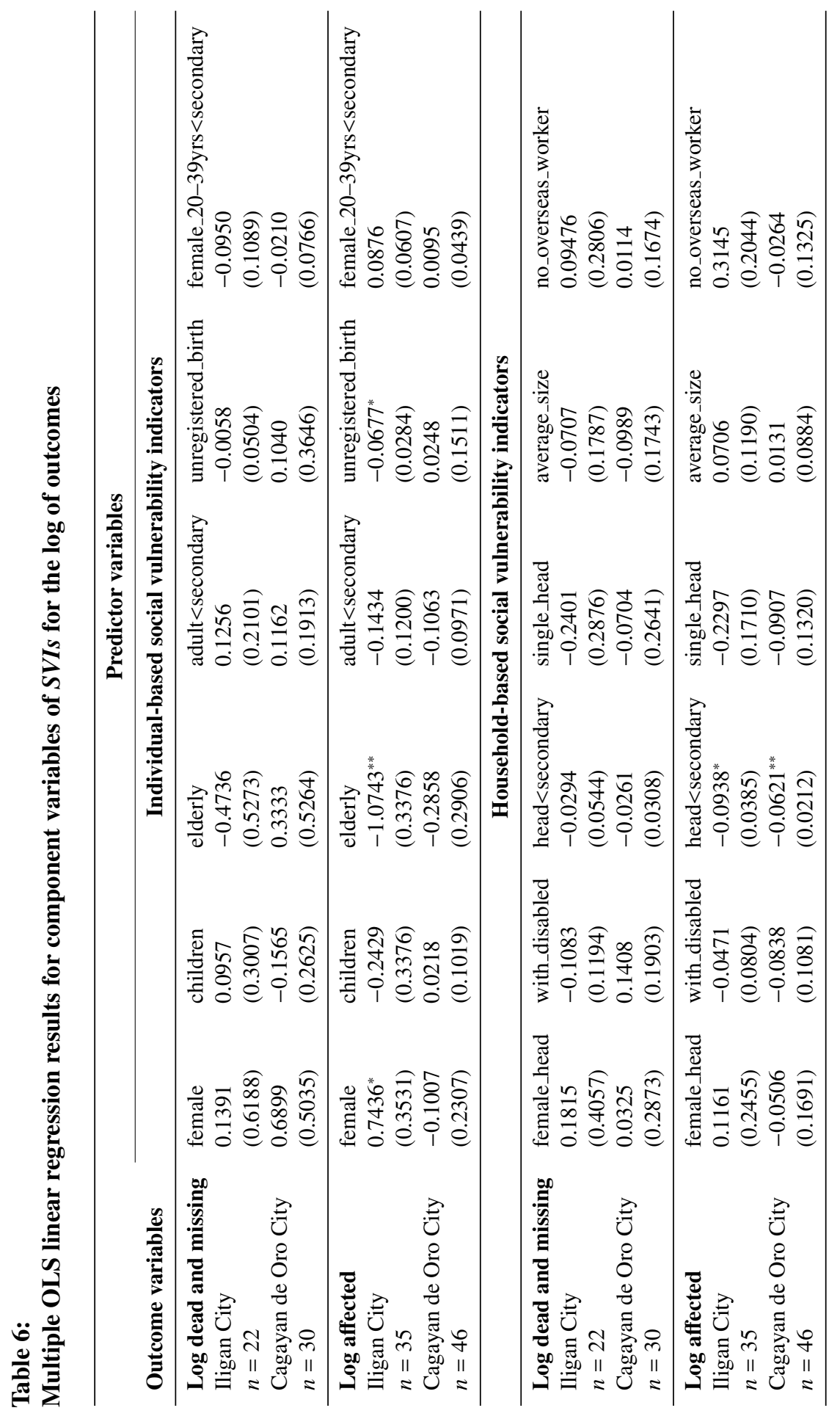




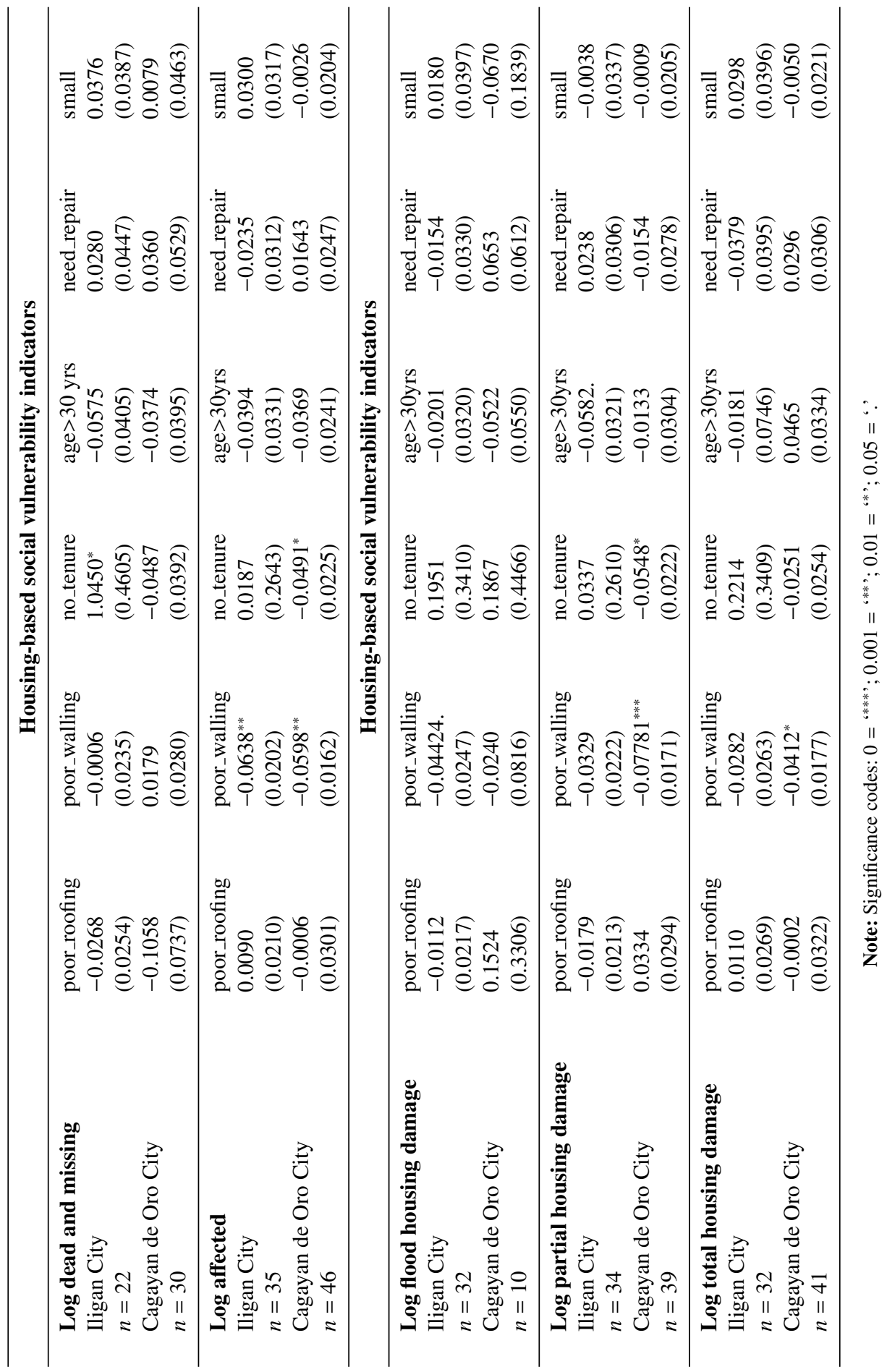


correspond to educational attainment and house structure stability, respectively; and both variables again have a negative relationship with the affected population dependent variable. For head<secondary, this means that the greater the percentage of household heads who had not finished secondary school, the lower the number of people affected. Like for the poor_walling variable, the inverse relationship obtained means that the higher the percentage of houses with poor walling materials, the lower the number of people affected. It is interesting to note that these two variables were also shown to have highly significant inverse relationships in the previous simple linear regression results (Table 5) for both case study sites, and for the same affected population outcome.

The result for the education variable can also be interpreted as follows: the higher the educational attainment of the household heads in the barangay, the higher the number of affected people. Like for the housing stability variable, we find that the more stable the walling materials of the houses in the barangay, the higher the number of affected individuals in the barangay. While these findings initially seem counterintuitive, based on observations conducted by combining a visual interpretation of satellite imagery (Figure 9) and GPS-based ground surveys comparing conditions before and after the disaster, it is apparent that the middleclass community zones located along the riverbanks were the main areas hit by TS Washi. Thus, it seems that the physical impact of a flood of this magnitude is much more significant than the demographic and socioeconomic characteristics of the affected population. In practical terms, it appears that the $C R F H$ zones, which are defined by the hydrogeomorphic conditions that are the most prone to severe flooding, are mainly inhabited by the middle class, a socioeconomic group who are generally less vulnerable than the poor. In technical terms, the $C R F H$ plays a major role as the defining variable for a priori exposure, significantly influencing the magnitude of loss and damage for both of the case study sites.

\section{Conclusion and recommendations}

The level of detail of the data compiled for this research, coupled with their broad coverage, made it possible to produce a geographically comprehensive and detailed social vulnerability assessment for the whole Philippines at the level of its most basic unit of governance, the barangay. Furthermore, the availability of raw and disaggregated census data allowed for the development of very specific indicators to capture social vulnerability that are adapted to the Philippine context. In this research, we attempted to develop vulnerability metrics at a relatively fine scale, while also including the validation of such quantitative and qualitative measurements with respect to the impacts of this type of flash flood hazard.

An ex-post validation of how social vulnerability and exposure determine flood impact at a detailed geographical level using the case study areas of Iligan and Cagayan de Oro Cities has revealed that the element of scale is a major factor to consider when making such assessments. Risk assessment at the national scale using 
Figure 9:

Pre and post TS Washi flood satellite images for Iligan and Cagayan de Oro Cities

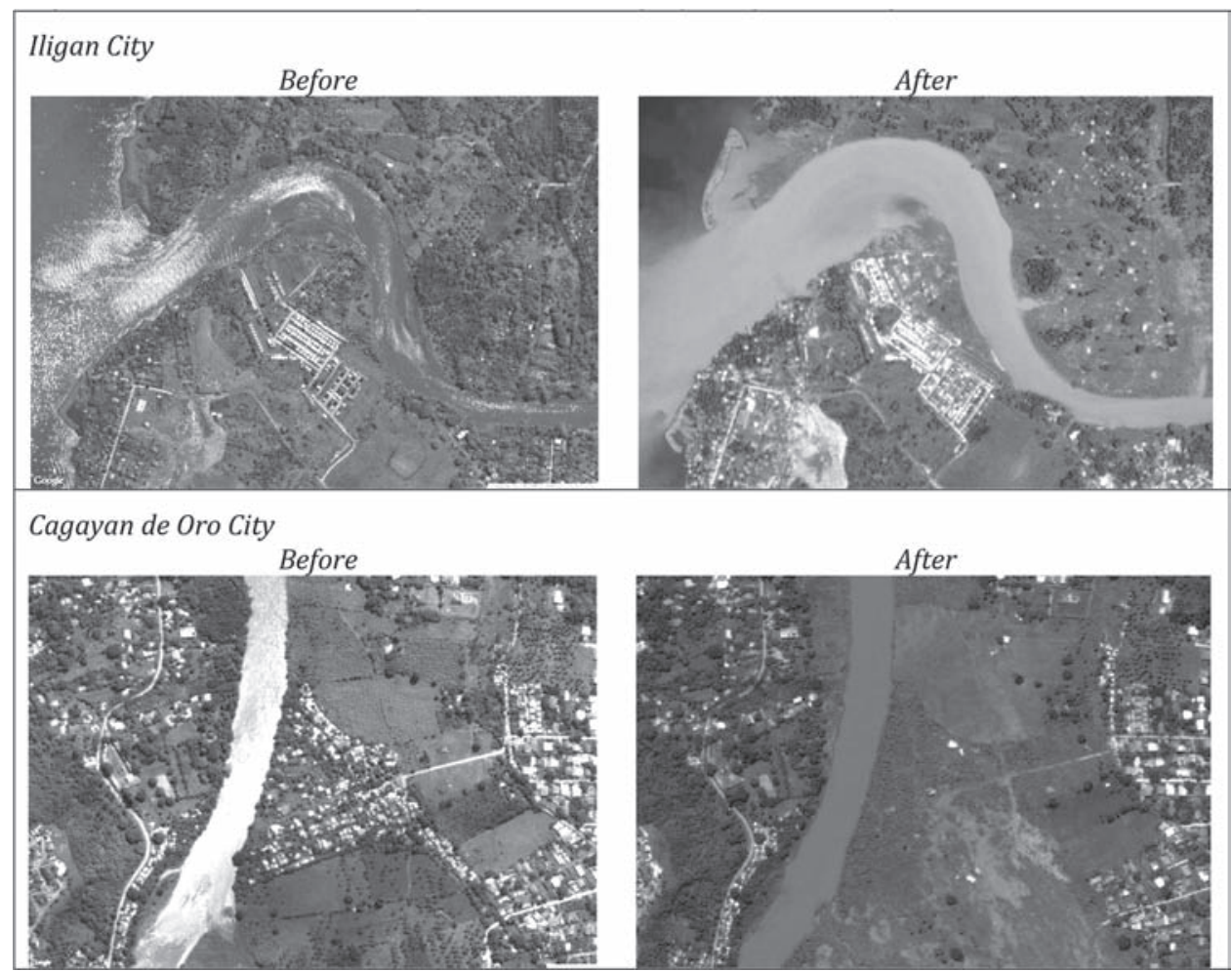

Source: Before images (C) Google; After images (c) Bing.

country-level data is important for collectively determining risk levels across nations and prioritizing needs. However, since hazards - and particularly flash floods - are spatially defined at the local level, identifying the populations who are exposed to such hazards through methods such as $C R F H$ area delineation can help to reduce risk. Although it has been established that there are direct relationships between vulnerability and disaster impact at the country level (Peduzzi et al. 2009), it is important that this evidence is applied at very local geographic scales when seeking to identify the populations who are most vulnerable to coastal flooding.

Although levels of social vulnerability may be measured accurately through indices such as those developed in this paper, the findings from this research suggest that the component of flood hazard exposure is more important in determining the magnitude of losses and damages than social vulnerability metrics. As the regression results revealed, the statistically significant social vulnerability indicators were actually inversely related to the outcome of the disasters. This does not, 
however, necessarily signify that there is an inverse correlation between social vulnerability and the tendency to be adversely affected by hazard events. In our analysis we found that having low SVI values does not connote a propensity to being affected by coastal river flooding, because middle-class housing had expanded into areas that had not been properly classified as flood-prone. The results show that exposure is more influential in determining losses and damages from disasters at this scale of analysis, and that other factors may be more significant than social vulnerability.

Using an SVI derived for counties in Germany exposed to river flooding, Fekete (2009) found a significant relationship between the vulnerability index scores and the affected groups per county. However, the nature and the scale of the floods Fekete considered were different from those investigated in this research. In the type of event being investigated here-i.e. an extreme flood event triggered by intense rainfall, and with a relatively low return probability (75 years) - much smaller watersheds were affected. It is possible that due to the very extreme nature of the flood event being investigated here, differential social vulnerability, as captured in the $S V I$ scores, did not significantly influence the outcomes.

The very high significance of the $C R F H$ variable shows that, in this context, exposure matters greatly. In the framework of the IPCC model on disaster risk, exposure is one of the major components in the management of risk. In an extreme hazard event such as TS Washi, differential vulnerability may disappear, and the most important component of the risk management framework shifts to the exposure of the population, and their ability to get out of harm's way. This observation also applies to recent events such as the 2004 Indian Ocean tsunami, the 2011 Tohoku tsunami, and the 2013 Super Typhoon Haiyan in the Central Philippines. The extreme nature of these events caused the exposure component to be the most significant determinant of the loss and damage levels, as the whole exposed population eventually became vulnerable, regardless of the initial states of vulnerability of the communities.

The delineation of the coastal river flood hazard $(C R F H)$ areas is important in identifying communities that are at high risk of being affected by coastal river flash floods. Once these areas are identified, government and other interest groups can then allocate resources to preparing for disasters, as such preparedness actions can spell the difference between life and death. In some cases, people might even need to be relocated to areas away from the flash flood danger zones. There should be a greater focus on urban expansion and development in hazard zones, with government agencies identifying the high-risk areas and declaring no-build zones in areas that are highly exposed.

The lack of consistent and uniform information at the barangay level throughout the country led us to use census data to develop proxy variables for vulnerability. We derived composite indicators of social vulnerability from the existing census fields in an effort to capture aspects of social vulnerability in the population. But in the end, the census database was designed with very specific objectives in mind, and we have to accept these limitations when we try to use the data for purposes other than those 
for which they were originally intended. Furthermore, as census data are collected every 10 years with an inter-decadal subset in-between, a more regular and more frequently updated survey specifically designed to measure vulnerability assessment and resilience building may be needed. As concern about climate change impacts grows, particularly in a country like the Philippines, which is exposed to a wide range of hazards and has relatively high levels of vulnerability (Welle et al. 2012), a regular vulnerability assessment would be a very useful tool for planning and for empowering communities as they slowly adapt to a rapidly changing environment.

\section{References}

Adger, W. N. et al. 2004. New indicators of vulnerability and adaptive capacity, Tyndall Centre for Climate Change Research Norwich. Available at: http://www.tyndall.ac.uk/ sites/default/files/it1_11.pdf [accessed September 30, 2015].

Birkmann, J. (ed.) 2006a. Measuring vulnerability to natural hazards - Towards disaster resilient societies, United Nations University.

Birkmann, J. 2006b. Measuring vulnerability to promote disaster-resilient societies: Conceptual frameworks and definitions. Measuring vulnerability to natural hazards: Towards disaster resilient societies, 9-54.

Birkmann, J. and N. Fernando 2008. Measuring revealed and emergent vulnerabilities of coastal communities to tsunami in Sri Lanka. Disasters, 32(1), 82-105.

Birkmann, J. and B. Wisner 2006. Measuring the un-measurable. UNU-EHS SOURCE, 5. Available at: http://www.ihdp.unu.edu/file/get/3962.pdf [accessed July 24, 2012].

Cardona, O. D. 2006. A system of indicators for disaster risk management in the Americas. In Measuring vulnerability to natural hazards: Towards disaster resilient societies, ed. J. Birkmann, pp. 189-209. New Delhi: TERI Press.

Carmines, E. G. and J. Woods, 2003. Index. In The Sage encyclopedia of social science research methods, eds M. S. Lewis-Beck, A. E. Bryman and T. F. F. Liao, pp.485-486. London: Sage Publications.

Commission on Filipinos Overseas, 2010. Stock estimate of overseas Filipinos. Available at: http://www.cfo.gov.ph/pdf/statistics/Stock\%202010.pdf [accessed August 13, 2013].

Convertino, M. et al., 2013. Epitomes of bottom-up hydro-geo-climatological analysis to face sea level rise in complex coastal ecosystems. In Climate vulnerability. Elsevier, 267282. Available at: http://linkinghub.elsevier.com/retrieve/pii/B9780123847034005025 [accessed December 22, 2014].

CRED, 2012. EM-DAT. EM-DAT: The International Disaster Database. Available at: http://www.emdat.be/about [accessed June 22, 2012].

Cutter, S. L. et al., 2008. A place-based model for understanding community resilience to natural disasters. Global Environmental Change, 18(4), 598-606.

Cutter, S. L., B. J. Boruff and W. L. Shirley 2003. Social Vulnerability to Environmental Hazards. Social Science Quarterly, 84(2), 242-261.

Diener, E. and E. Suh 1997. Measuring quality of life: Economic, social, and subjective indicators. Social indicators research, 40(1-2), 189-216. 
Farr, T. G. et al., 2007. The shuttle radar topography mission. Reviews of Geophysics, 45. Available at: http://www2.jpl.nasa.gov/srtm/SRTM_paper.pdf [accessed May 20, 2009].

Fekete, A., 2009. Validation of a social vulnerability index in context to river-floods in Germany. Natural Hazards and Earth System Sciences, 9(2), 393-403.

Field, C. B. et al., 2014. Summary for policymakers, Cambridge, UK; New York, NY, USA: IPCC.

GADM, 2009. Global administrative areas. Available at: http://www.gadm.org/ [accessed June 6, 2012].

Gall, M., 2007. Indices of social vulnerability to natural hazards: A comparative evaluation. Available at: http://webra.cas.sc.edu/hvri/education/docs/Melanie_Gall_2007. pdf [accessed October 20, 2012].

Grimaldi, S. et al., 2013. Flood mapping in ungauged basins using fully continuous hydrologic-hydraulic modeling. Journal of Hydrology, 487, 39-47.

Grimaldi, S., A. Petroselli and F. Nardi 2012. Convolution of linear system using geomorphological watershed information. In pp. 1800-1803. Available at: http://scitation. aip.org/content/aip/proceeding/aipcp/10.1063/1.4756527 [accessed December 22, 2014].

Grimaldi, S., V. Teles and R. L. Bras 2004. Sensitivity of a physically based method for terrain interpolation to initial conditions and its conditioning on stream location. Earth Surface Processes and Landforms, 29(5), 587-597.

Ignacio, J. A. and S. Henry, 2013a. Assessing changes in village-level social vulnerability based on census data. In Abstracts. XXVII International Population Conference. Busan, Korea: IUSSP. Available at: http://www.iussp.org/en/event/17/programme/paper/5180.

Ignacio, J. A. and S. Henry, 2013b. Assessing the vulnerability of populations at high risk to coastal river flooding in the Philippines. In From social vulnerability to resilience: Measuring progress toward disaster risk reduction, eds S. L. Cutter and C. Corendea. Bonn, Germany: United Nations University Institute for Environment and Human Security. Available at: https://www.ehs.unu.edu/file/get/11051.pdf [accessed May 16, 2013].

IPCC (eds) 2012. Managing the risks of extreme events and disasters to advance climate change adaptation. A special report of Working Groups I and II of the Intergovernmental Panel on Climate Change, Cambridge: Cambridge University Press.

Kasperson, J. X. et al., 2001. International workshop on vulnerability and global environmental change. SEI Risk and vulnerability programme report, 1. Available at: http://www.start.org/Program/advanced_institute3_web/p3_documents_folder/ Kasperson_etal_wkshp-rpt.pdf [accessed October 29, 2012].

King, D. and C. MacGregor 2000. Using social indicators to measure community vulnerability to natural hazards. Australian Journal of Emergency Management, 15(3), 52-57.

Lavell, A., E. Mansilla and others, 2003. Local level risk management: concept and practices. CEPREDENAC-UNDP, Quito, Ecuador.

Lutz, W., J. C. Cuaresma and W. Sanderson 2008. The demography of educational attainment and economic growth. Science, 319(5866), 1047-1048.

Manfreda, S. et al., 2014. Investigation on the use of geomorphic approaches for the delineation of flood prone areas. Journal of Hydrology, 517, 863-876. 
Morrissey, J. and A. Oliver-Smith 2013. Perspectives on non-economic loss and damage. Available at: http://www.loss-and-damage.net/download/7213.pdf [accessed December 19, 2013].

NAMRIA, 1:50,000 Topographical map series of the Philippines.

Nardi, F. et al., 2013. Comparing a large-scale DEM-based floodplain delineation algorithm with standard flood maps: The Tiber River Basin case study: Large-scale DEM-based floodplain delineation. Irrigation and Drainage, 62(S2), 11-19.

Nardi, F. et al., 2008. Hydrogeomorphic properties of simulated drainage patterns using digital elevation models: The flat area issue / Propriétés hydro-géomorphologiques de réseaux de drainage simulés à partir de modèles numériques de terrain: la question des zones planes. Hydrological Sciences Journal, 53(6), 1176-1193.

Nardi, F., E. R. Vivoni and S. Grimaldi 2006. Investigating a floodplain scaling relation using a hydrogeomorphic delineation method. Water Resources Research, 42, W09409.

Nardo, M. et al., 2005. Handbook on constructing composite indicators: Methodology and user guide. OECD Publishing.

Openshaw, S., 1983. The modifiable areal unit problem. Norwich, Norfolk: Geo Books.

Peduzzi, P. et al., 2009. Assessing global exposure and vulnerability towards natural hazards: The Disaster Risk Index. Natural Hazards and Earth System Sciences, 9(4), 1149-1159.

Philippine Council on Women, 2014. Factsheet for Filipino women and men 2014. Manila, Philippines: Philippine Council on Women.

Philippine Information Authority, 2012. Barangay officials urged to amicably settle boundary disputes. Available at: http://www.pia.gov.ph/news/index.php?article=1541331802263 [accessed October 28, 2012].

Racelis, R. H. and J. M. I. Salas 2008. A note on defining the dependent population based on age, Philippine Institute for Development Studies. Available at: http://www.eaber.org/ sites/default/files/documents/PIDS_Racelis_2008_02.pdf [accessed October 20, 2012].

Regional Development Council X, 2012. Strategic action plan for the rehabilitation and recovery of the areas affected by Tropical Storm Sendong (Washi), Cagayan de Oro City, Philippines. Available at: http://reliefweb.int/sites/reliefweb.int/files/resources/Full\% 20Report_608.pdf [accessed October 29, 2012].

Republic of the Philippines, 1992. Republic Act No. 7432: An act to maximize the contribution of senior citizens to nation building, grant benefits and special privileges and for other purposes, Department of Social Welfare and Development. Available at: http://books.google.com.ph/books?id=UkN-GwAACAAJ.

Rygel, L., D. O'Sullivan and B. Yarnal 2006. A method for constructing a social vulnerability index: An application to hurricane storm surges in a developed country. Mitigation and Adaptation Strategies for Global Change, 11(3), 741-764.

Striessnig, E., W. Lutz and A. G. Patt 2013. Effects of educational attainment on climate risk vulnerability. Ecology $\mathcal{G}$ Society, 18(1). 2013.

UNISDR, 2005. Hyogo framework for action 2005-2015: Building the resilience of nations and communities to disasters. In Extract from the final report of the World Conference on Disaster Reduction (A/CONF. 206/6). Available at: http://www.unisdr.org/ files/1037_hyogoframeworkforactionenglish.pdf. 
Warner, K. and K. van der Geest 2013. Loss and damage from climate change: Local-level evidence from nine vulnerable countries. International Journal of Global Warming, 5(4), 367-386.

Welle, T. et al. 2012. World Risk Report 2012, Berlin, Germany: United Nations University, Institute for Environment and Human Security.

Xavier University Engineering Resource Center, 2011. Typhoon Washi flood damage map of Cagayan de Oro City.

\section{Appendix A: Losses and damages in the case study areas resulting from TS Washi}

\section{A.1 lligan city}

Missing persons Table A.1 shows the profile of the 1,023 missing persons reported in 19 barangays. The results show that most of the missing were reported in Hinaplanon (59.3\%), while smaller shares were reported in Santiago (17.3\%) and Santa Filomena (7.2\%).

The missing were almost evenly spread between the sexes, although the share of the females is slightly higher than the share of males ( $56 \%$ vs $44 \%$ ). The mean age of the missing was relatively young, at around 23 years old, with almost no significant difference between the sexes. Of the missing, one in five were children under five years old, around $40 \%$ were under age 15 , and an equal percentage were in the prime ages of 15-59. At least $6 \%$ of the missing were people aged 60 and older. There were more females than males among the missing for all age groups except for infants (<one year old).

Dead persons A total of 148 people were reported dead in 12 barangays. Most of of the cases were in Hinaplanon (59.4\%), followed by in Santa Filomena, (13.5\%) and in Upper Hinaplanon $(10.1 \%)$. In terms of the sex structure, slightly more females $(57.4 \%)$ than males $(42.6 \%)$ perished as a result of the flooding. The average age of those who died was 30.8 , with the women who perished being about four years older than the men (32.7 vs. 28.2, respectively). The gender difference in age was, however, not statistically different.

A closer examination of the age structure of the mortality statistics indicates that there were three cases of infant mortality (i.e. of infants aged under one year) associated with this natural disaster. Almost one-fifth of those who died were aged 1-4, another one-fifth were in the 5-14 age group, while 44\% were in their prime years (ages 15-59). A disproportionate share of those who died were older people $(17.7 \%)$. As of the 2010 census, older people constituted only $5.7 \%$ of the population in the 12 barangays that reported deaths.

An analysis of the age structure of the mortality by sex also reveals that more older females $(10.8 \%)$ than older males $(6.7 \%)$ died. Almost $19 \%$ of the females 
Table A.1:

Iligan City barangays with registered dead and missing victims

\begin{tabular}{lrrrrrrr}
\hline Barangay name & $\begin{array}{r}\text { Total missing and } \\
\text { \% of tot. pop. }\end{array}$ & \multicolumn{2}{c}{$\begin{array}{r}\text { Total dead and } \\
\text { \% of tot. pop. }\end{array}$} & $\begin{array}{r}\text { Total affected and } \\
\text { \% of tot. pop. }\end{array}$ & $\begin{array}{r}\mathbf{2 0 1 1} \\
\text { population* }\end{array}$ \\
\hline Hinaplanon & 84 & $0.57 \%$ & 607 & $4.14 \%$ & 15,636 & $106.74 \%$ & 14,648 \\
Santiago & 11 & $0.12 \%$ & 177 & $1.85 \%$ & 8,461 & $88.59 \%$ & 9,551 \\
Santa Filomena & 20 & $0.26 \%$ & 74 & $0.97 \%$ & 3,074 & $40.40 \%$ & 7,608 \\
Mandulog & 2 & $0.07 \%$ & 38 & $1.34 \%$ & 1,647 & $58.05 \%$ & 2,837 \\
Upper Hinaplanon & 15 & $0.23 \%$ & 34 & $0.51 \%$ & 5,717 & $85.78 \%$ & 6,665 \\
San Roque & 5 & $0.12 \%$ & 32 & $0.79 \%$ & 3,854 & $95.51 \%$ & 4,035 \\
Bonbonon & - & - & 12 & $0.81 \%$ & 872 & $58.84 \%$ & 1,482 \\
Digkilaan & 1 & $0.02 \%$ & 11 & $0.27 \%$ & 1,259 & $30.35 \%$ & 4,148 \\
Bagong Silang & - & - & 10 & $0.17 \%$ & 5,153 & $86.03 \%$ & 5,990 \\
Abuno & - & - & 7 & $0.15 \%$ & 139 & $2.95 \%$ & 4,717 \\
Tubod & 2 & $0.01 \%$ & 6 & $0.02 \%$ & 8,092 & $24.20 \%$ & 33,442 \\
Tambacan & 4 & $0.02 \%$ & 5 & $0.03 \%$ & 9,876 & $55.62 \%$ & 17,757 \\
Rogongon & - & - & 2 & $0.04 \%$ & 1,814 & $38.07 \%$ & 4,765 \\
Kalilangan & - & - & 2 & $0.15 \%$ & 150 & $11.54 \%$ & 1,300 \\
Panoroganan & - & - & 2 & $0.05 \%$ & 163 & $3.68 \%$ & 4,424 \\
Dalipuga & - & - & 1 & $0.01 \%$ & 1,132 & $5.82 \%$ & 19,458 \\
Pala-o & - & - & 1 & $0.01 \%$ & 2,677 & $28.34 \%$ & 9,445 \\
Poblacion & - & - & 1 & $0.03 \%$ & 949 & $26.42 \%$ & 3,592 \\
Ubaldo Laya & - & - & 1 & $0.01 \%$ & 3,569 & $31.93 \%$ & 11,179 \\
Luinab & 2 & $0.02 \%$ & - & - & 392 & $4.41 \%$ & 8,893 \\
Santo Rosario & 1 & $0.05 \%$ & - & - & 1,576 & $75.05 \%$ & 2,100 \\
Hindang & 1 & $0.08 \%$ & - & - & 3 & $0.24 \%$ & 1,237 \\
\hline Total & 148 & $0.08 \%$ & 1,023 & $0.57 \%$ & 76,205 & $42.51 \%$ & 179,275 \\
\hline
\end{tabular}

Note: *Projected from 2007 and 2010 population census data.

who died were elderly, compared to about $16 \%$ of the males. These results indicate that older people, and especially older women, are particularly vulnerable to disaster risks.

Affected persons A total of 94,611 individuals were surveyed and registered with the Iligan City government as having been affected by the flooding. Hinaplanon had the most affected individuals (16.5\%), followed by Tambacan $(10.4 \%)$ and Santiago $(8.94 \%)$. Our examination of the demographic distribution of the affected persons did not reveal any significant findings with respect to age, sex, or educational attainment.

Table A.2 presents the 22 barangays that had registered missing and/or dead individuals, with additional information on the number of affected individuals in each barangay, together with its 2010 population. An additional 13 barangays not shown in Table A.2 had individuals affected by the flood, but no dead or missing. 
Table A.2:

Iligan City barangays that sustained varying degrees of damage to housing units

\begin{tabular}{|c|c|c|c|c|c|c|c|}
\hline \multirow{2}{*}{$\begin{array}{l}\text { Barangay } \\
\text { Hinaplanon }\end{array}$} & \multicolumn{2}{|c|}{$\begin{array}{l}\text { Total damage and } \\
\% \text { of tot. housing }\end{array}$} & \multicolumn{2}{|c|}{$\begin{array}{c}\text { Partial damage and } \\
\% \text { of tot. housing }\end{array}$} & \multicolumn{2}{|c|}{$\begin{array}{l}\text { Flooded only and } \\
\% \text { of tot. housing }\end{array}$} & \multirow{2}{*}{$\begin{array}{r}\text { Total housing } \\
\text { units in 2011* } \\
3,555\end{array}$} \\
\hline & 1,499 & $42.17 \%$ & 1,675 & $47.12 \%$ & 417 & $11.73 \%$ & \\
\hline Upper Hinaplanon & 699 & $49.47 \%$ & 352 & $24.91 \%$ & 158 & $11.18 \%$ & 1,413 \\
\hline Santa Filomena & 481 & $27.38 \%$ & 179 & $10.19 \%$ & 41 & $2.33 \%$ & 1,757 \\
\hline Santiago & 461 & $19.80 \%$ & 611 & $26.25 \%$ & 793 & $34.06 \%$ & 2,328 \\
\hline San Roque & 372 & $39.91 \%$ & 286 & $30.69 \%$ & 282 & $30.26 \%$ & 932 \\
\hline Tubod & 125 & $1.73 \%$ & 505 & $6.98 \%$ & 1,205 & $16.65 \%$ & 7,238 \\
\hline Tambacan & 107 & $2.79 \%$ & 352 & $9.18 \%$ & 1,698 & $44.28 \%$ & 3,835 \\
\hline Mandulog & 90 & $13.82 \%$ & 77 & $11.83 \%$ & 156 & $23.96 \%$ & 651 \\
\hline Rogongon & 82 & $7.93 \%$ & 33 & $3.19 \%$ & 223 & $21.57 \%$ & 1,034 \\
\hline Digkilaan & 79 & $8.09 \%$ & 109 & $11.17 \%$ & 98 & $10.04 \%$ & 976 \\
\hline Mahayahay & 77 & $3.62 \%$ & 467 & $21.95 \%$ & 1,037 & $48.73 \%$ & 2,128 \\
\hline Pala-o & 77 & $3.60 \%$ & 244 & $11.42 \%$ & 268 & $12.54 \%$ & 2,137 \\
\hline Bonbonon & 77 & $25.16 \%$ & 70 & $22.88 \%$ & 46 & $15.03 \%$ & 306 \\
\hline Ubaldo Laya & 52 & $2.02 \%$ & 232 & $8.99 \%$ & 508 & $19.69 \%$ & 2,580 \\
\hline Bagong Silang & 29 & $2.01 \%$ & 227 & $15.73 \%$ & 866 & $60.01 \%$ & 1,443 \\
\hline Panoroganan & 29 & $4.30 \%$ & 7 & $1.04 \%$ & 5 & $0.74 \%$ & 675 \\
\hline Tibanga & 23 & $1.19 \%$ & 39 & $2.02 \%$ & 38 & $1.97 \%$ & 1,933 \\
\hline Kalilangan & 15 & $5.62 \%$ & 1 & $0.37 \%$ & 10 & $3.75 \%$ & 267 \\
\hline Dulag & 13 & $5.96 \%$ & 6 & $2.75 \%$ & - & - & 218 \\
\hline Puga-an & 12 & $0.74 \%$ & 46 & $2.83 \%$ & 120 & $7.38 \%$ & 1,626 \\
\hline Tipanoy & 9 & $0.30 \%$ & 83 & $2.73 \%$ & 401 & $13.17 \%$ & 3,044 \\
\hline Luinab & 9 & $0.45 \%$ & 19 & $0.94 \%$ & 64 & $3.17 \%$ & 2,022 \\
\hline Mainit & 7 & $1.23 \%$ & 9 & $1.58 \%$ & 3 & $0.53 \%$ & 570 \\
\hline Santo Rosario & 6 & $1.04 \%$ & 12 & $2.08 \%$ & 328 & $56.85 \%$ & 577 \\
\hline Dalipuga & 4 & $0.08 \%$ & 28 & $0.58 \%$ & 196 & $4.08 \%$ & 4,799 \\
\hline Lanipao & 4 & $0.79 \%$ & 13 & $2.57 \%$ & 16 & $3.17 \%$ & 505 \\
\hline Abuno & 3 & $0.27 \%$ & 14 & $1.26 \%$ & 14 & $1.26 \%$ & 1,115 \\
\hline Del Carmen & 2 & $0.10 \%$ & 135 & $6.78 \%$ & 630 & $31.63 \%$ & 1,992 \\
\hline Kiwalan & 2 & $0.14 \%$ & 7 & $0.48 \%$ & 1 & $0.07 \%$ & 1,457 \\
\hline Acmac & 1 & $0.07 \%$ & 4 & $0.29 \%$ & 4 & $0.29 \%$ & 1,378 \\
\hline Kabacsanan & 1 & $0.22 \%$ & 2 & $0.44 \%$ & - & - & 453 \\
\hline Hindang & 1 & $0.37 \%$ & - & - & - & - & 269 \\
\hline Poblacion & - & - & 20 & $1.69 \%$ & 220 & $18.57 \%$ & 1,185 \\
\hline San Miguel & - & - & 11 & $1.14 \%$ & 482 & $49.90 \%$ & 966 \\
\hline Villaverde & - & - & 9 & $0.72 \%$ & 254 & $20.42 \%$ & 1,244 \\
\hline Total & 10,582 & $18.06 \%$ & 5,884 & $10.04 \%$ & 4,448 & $7.59 \%$ & 58,608 \\
\hline
\end{tabular}

Note: *Projected from 2000 and 2010 housing census data. 
It is worth noting that in Hinaplanon the total number of victims (missing, dead, and affected) was high relative to its projected 2011 population. The projected population based on a geometric growth rate between the census years of 2007 to 2010 should have been only 14,648, while the total number of documented victims was 16,327 . The discrepancy can be partly explained by the completion of new housing projects in the barangay, as can be seen in multi-date high resolution satellite images analyzed for the area, as well as in the total number of housing units (Table A.2).

Damage to housing A total of 20,914 housing units were damaged in Iligan City due to the TS Washi flood. The largest share of the damages occurred in Hinaplanon (17.2\%), followed by Tambacan (10.3\%), and Santiago (8.9\%). Table A.4 provides the full details of the number of housing units that experienced varying degrees of damage per barangay, together with the total number of housing units in 2011, as projected from the 2010 census. Totally damaged houses were totally destroyed or washed out; partially damaged houses sustained damage to parts of the structure but were still repairable; while flooded only houses did not incur any structural harm, but items within the houses were damaged, such as furniture, appliances, and other personal belongings.

\section{A.2 Cagayan de Oro city}

Missing persons Table A.3 shows the profile of the 363 missing persons reported in 17 barangays. The results show that most of the missing persons were reported in Macasandig (72.2\%), while much smaller shares were reported in 13 and Balulang (7.2\% in both).

Roughly equal shares of males and females (49\% vs 51\%) went missing, while the mean age of the missing was even younger than in Iligan City, at around 21.8. Of the missing, around one in four were children under age five, around $50.4 \%$ were under age 15 , and $36.1 \%$ were in the prime ages of $15-59$. At least $13.5 \%$ of those missing were aged 60 and older. The sex distribution was nearly equal across all of the age groups.

Dead persons A total of 569 people were reported dead in Cagayan de Oro City. Of this total number, there was no information on the barangay for 90 cases. Thus, only 479 cases could be assigned to 24 barangays. The largest share of these cases were in Macasandig (42.4\%), while smaller shares were in $13(23.8 \%)$ and Balulang (15.9\%). Slightly fewer males (45.5\%) than females $(54.5 \%)$ perished as a result of the flooding. The average age of those who died was 32.4, with women being about two and a half years older than men on average (33.5 years vs. 31.1 years, respectively). Like in Iligan City, the gender differences across age groups were not statistically significant. 
Table A.3:

Cagayan de Oro City barangays with registered dead and missing victims

\begin{tabular}{lrrrrrrr}
\hline Barangay & $\begin{array}{r}\text { Total dead and } \\
\text { \% of tot. pop. }\end{array}$ & $\begin{array}{r}\text { Total missing and } \\
\text { \% }\end{array}$ & $\begin{array}{r}\text { Total affected and } \\
\text { \% }\end{array}$ of tot. pop. & $\begin{array}{r}\mathbf{2 0 1 1} \\
\text { population* }\end{array}$ \\
\hline Macasandig & 203 & $0.84 \%$ & 262 & $1.09 \%$ & 3,851 & $15.98 \%$ & 24,103 \\
Barangay 13 & 114 & $4.96 \%$ & 29 & $1.26 \%$ & 1,392 & $60.52 \%$ & 2,300 \\
Balulang & 76 & $0.23 \%$ & 29 & $0.09 \%$ & 6,221 & $19.10 \%$ & 32,575 \\
Carmen & 35 & $0.05 \%$ & 12 & $0.02 \%$ & 9,376 & $12.77 \%$ & 73,420 \\
Barangay 15 & 11 & $0.36 \%$ & 6 & $0.20 \%$ & 504 & $16.47 \%$ & 3,061 \\
Consolacion & 7 & $0.07 \%$ & 1 & $0.01 \%$ & 1,005 & $10.02 \%$ & 10,032 \\
Puntod & 4 & $0.02 \%$ & - & - & 2,988 & $16.52 \%$ & 18,089 \\
Canitoan & 3 & $0.02 \%$ & 2 & $0.01 \%$ & 1,600 & $10.21 \%$ & 15,664 \\
Kauswagan & 3 & $0.01 \%$ & - & - & 6,752 & $19.23 \%$ & 35,112 \\
Iponan & 3 & $0.01 \%$ & - & - & 3,696 & $16.82 \%$ & 21,980 \\
Tablon & 3 & $0.02 \%$ & - & - & 523 & $2.83 \%$ & 18,451 \\
Barangay 14 & 2 & $0.51 \%$ & 1 & $0.25 \%$ & - & - & 395 \\
Cugman & 2 & $0.01 \%$ & - & - & 773 & $3.71 \%$ & 20,835 \\
Mambuaya & 2 & $0.07 \%$ & - & - & 3 & $0.11 \%$ & 2,726 \\
Patag & 2 & $0.01 \%$ & - & - & - & - & 17,230 \\
Bayanga & 1 & $0.04 \%$ & 8 & $0.28 \%$ & 8 & $0.28 \%$ & 2,849 \\
Camaman-an & 1 & $0.00 \%$ & 4 & $0.02 \%$ & 38 & $0.15 \%$ & 25,001 \\
Lumbia & 1 & $0.01 \%$ & 1 & $0.01 \%$ & 100 & $0.73 \%$ & 13,640 \\
Barangay 18 & 1 & $0.06 \%$ & - & - & 816 & $52.82 \%$ & 1,545 \\
Bonbon & 1 & $0.01 \%$ & - & - & 536 & $5.66 \%$ & 9,478 \\
Barangay 17 & 1 & $0.04 \%$ & - & - & 508 & $21.36 \%$ & 2,378 \\
Baikingon & 1 & $0.04 \%$ & - & - & 184 & $7.43 \%$ & 2,476 \\
Bayabas & 1 & $0.01 \%$ & - & - & 25 & $0.18 \%$ & 13,789 \\
Puerto & 1 & $0.01 \%$ & - & - & - & - & 12,501 \\
Nazareth & - & - & 2 & $0.02 \%$ & 258 & $2.44 \%$ & 10,563 \\
Tumpagon & - & - & 2 & $0.09 \%$ & 170 & $7.30 \%$ & 2,330 \\
Bulua & - & - & 1 & $0.00 \%$ & 1,477 & $4.48 \%$ & 32,988 \\
Gusa & - & - & 1 & $0.00 \%$ & 617 & $2.32 \%$ & 26,571 \\
Pagatpat & - & - & 1 & $0.02 \%$ & 428 & $8.03 \%$ & 5,328 \\
Barangay 22 & - & - & 1 & $0.05 \%$ & - & - & 1,902 \\
\hline Total & $479 * *$ & $0.10 \%$ & 363 & $0.08 \%$ & 43,849 & $9.55 \%$ & 459,312 \\
\hline & & & & & & & \\
\hline
\end{tabular}

Note: *Projected from 2007 and 2010 data. ${ }^{* *}$ There were 90 victims who could not be located by barangay.

Looking at the age structure of the mortality statistics, we found a higher rate of infant mortality in Cagayan de Oro City, at 15 deaths $(3.1 \%)$, and a smaller share of deaths among those aged 1-4 (7.7\%). Seventeen percent of the deaths occurred among the 5-14 age group. Similar to the share found in Iligan City, 43.4\% of those who died were between 15 and 59 years of age. A high proportion of the casualties $(24.0 \%)$ were aged 60 and older. This share was even higher relative to the group's share of the entire population than the share found in Iligan City. As of the 2010 
census, older people constituted only $4.9 \%$ of the population in the 24 barangays that reported deaths.

An analysis of the age structure of the mortality by sex also revealed that among all those who died, around $12.5 \%$ were elderly females while $11 \%$ were elderly males. Around $23.2 \%$ of the females and $24.1 \%$ of the males who died were elderly. There was no statistically significant difference in sex among the elderly casualties, but as was the case in Iligan City, the elderly in general were more vulnerable to flood risk.

Affected persons A total of 47,526 individuals were surveyed and registered with the Cagayan de Oro City government as having been affected by the flooding. Carmen was the barangay that had the most affected individuals (21.4\%), followed by Kauswagan $(15.4 \%)$ and Balulang (14.2\%). The available data for the affected population in Cagayan de Oro City was not disaggregated beyond the barangay level, and did not have a further breakdown of demographic characteristics.

Damage to housing A total of 20,914 housing units were damaged in Cagayan de Oro City due to the TS Washi-triggered floods. Most of the housing damages occurred in the barangays of Carmen (17.8\%), Balulang (13.3\%), and Kauswagan (9.3\%). Table A.4 provides the full details of the number of housing units that experienced varying degrees of damage per barangay, together with the total number of housing units from the 2010 census. It is important to note that Macasandig had the highest number of houses that were totally damaged, while in Kauswagan most of the damaged houses were merely inundated.

Table A.4:

Cagayan de Oro City barangays that sustained varying degrees of damage to housing

\begin{tabular}{lrrrrrrr}
\hline Barangay & $\begin{array}{c}\text { Total damage and } \\
\text { \% of tot. housing }\end{array}$ & $\begin{array}{c}\text { Partial damage and } \\
\text { \% of tot. housing }\end{array}$ & $\begin{array}{c}\text { Flooded only and } \\
\text { \% of tot. housing }\end{array}$ & $\begin{array}{r}\text { Total housing } \\
\text { units in 2011* }\end{array}$ \\
\hline Macasandig & 1,013 & $17.20 \%$ & 318 & $5.40 \%$ & - & - & 5,890 \\
Carmen & 845 & $4.66 \%$ & 1,499 & $8.27 \%$ & - & - & 18,134 \\
Balulang & 700 & $7.36 \%$ & 1,050 & $11.04 \%$ & - & - & 9,515 \\
Barangay 13 & 308 & $55.10 \%$ & 40 & $7.16 \%$ & - & - & 559 \\
Iponan & 116 & $1.76 \%$ & 707 & $10.75 \%$ & 26 & $0.40 \%$ & 6,577 \\
Kauswagan & 102 & $1.20 \%$ & 82 & $0.97 \%$ & 1,504 & $17.72 \%$ & 8,487 \\
Bulua & 92 & $1.15 \%$ & 221 & $2.77 \%$ & 815 & $10.22 \%$ & 7,972 \\
Canitoan & 90 & $2.43 \%$ & 310 & $8.36 \%$ & - & - & 3,710 \\
Barangay 15 & 73 & $8.90 \%$ & 11 & $1.34 \%$ & - & - & 820 \\
Consolacion & 69 & $2.52 \%$ & 172 & $6.28 \%$ & - & - & 2,739 \\
Tuburan & 53 & $16.51 \%$ & 18 & $5.61 \%$ & - & - & 321 \\
Pagatpat & 52 & $3.56 \%$ & 107 & $7.32 \%$ & 123 & $8.42 \%$ & 1,461 \\
Tablon & 49 & $0.96 \%$ & 84 & $1.65 \%$ & - & - & 5,100 \\
\hline
\end{tabular}

Continued 
Table A.4:

Continued

\begin{tabular}{|c|c|c|c|c|c|c|c|}
\hline \multirow{2}{*}{$\frac{\text { Barangay }}{\text { Bonbon }}$} & \multicolumn{2}{|c|}{$\begin{array}{l}\text { Total damage and } \\
\% \text { of tot. housing }\end{array}$} & \multicolumn{2}{|c|}{$\begin{array}{l}\text { Partial damage and } \\
\% \text { of tot. housing }\end{array}$} & \multicolumn{2}{|c|}{$\begin{array}{l}\text { Flooded only and } \\
\% \text { of tot. housing }\end{array}$} & \multirow{2}{*}{$\begin{array}{r}\begin{array}{c}\text { Total housing } \\
\text { units in 2011* }\end{array} \\
2,297\end{array}$} \\
\hline & 39 & $1.70 \%$ & 90 & $3.92 \%$ & - & - & \\
\hline Cugman & 37 & $0.73 \%$ & 140 & $2.77 \%$ & - & - & 5,052 \\
\hline Agusan & 36 & $0.98 \%$ & 45 & $1.23 \%$ & - & - & 3,659 \\
\hline Tumpagon & 34 & $6.10 \%$ & - & - & - & - & 557 \\
\hline Gusa & 31 & $0.47 \%$ & 109 & $1.66 \%$ & - & - & 6,549 \\
\hline Pigsag-an & 29 & $12.03 \%$ & 3 & $1.24 \%$ & - & - & 241 \\
\hline Puntod & 25 & $0.52 \%$ & 474 & $9.91 \%$ & - & - & 4,783 \\
\hline Nazareth & 22 & $0.75 \%$ & 10 & $0.34 \%$ & - & - & 2,922 \\
\hline Lumbia & 20 & $0.50 \%$ & 14 & $0.35 \%$ & - & - & 3,994 \\
\hline Indahag & 17 & $0.97 \%$ & 19 & $1.08 \%$ & - & - & 1,754 \\
\hline Baikingon & 16 & $2.42 \%$ & 27 & $4.08 \%$ & - & - & 662 \\
\hline Barangay 7 & 16 & $11.11 \%$ & 23 & $15.97 \%$ & - & - & 144 \\
\hline Macabalan & 15 & $0.31 \%$ & 59 & $1.24 \%$ & - & - & 4,762 \\
\hline Barangay 6 & 15 & $44.12 \%$ & 7 & $20.59 \%$ & - & - & 34 \\
\hline Pagalungan & 14 & $3.16 \%$ & 2 & $0.45 \%$ & - & - & 443 \\
\hline Dansolihon & 12 & $1.01 \%$ & 4 & $0.34 \%$ & - & - & 1,194 \\
\hline Tignapoloan & 11 & $1.12 \%$ & 1 & $0.10 \%$ & - & - & 981 \\
\hline Barangay 10 & 10 & $6.85 \%$ & 56 & $38.36 \%$ & - & - & 146 \\
\hline San Simon & 9 & $2.59 \%$ & 92 & $26.51 \%$ & - & - & 347 \\
\hline FS Catanico & 9 & $2.05 \%$ & 57 & $12.98 \%$ & - & - & 439 \\
\hline Barangay 1 & 7 & $4.12 \%$ & 20 & $11.76 \%$ & 142 & $83.53 \%$ & 170 \\
\hline Barangay 17 & 3 & $0.51 \%$ & 95 & $16.07 \%$ & - & - & 591 \\
\hline Barangay 18 & 2 & $0.47 \%$ & 182 & $42.92 \%$ & - & - & 424 \\
\hline Camaman-an & 2 & $0.03 \%$ & 7 & $0.12 \%$ & 127 & $2.13 \%$ & 5,969 \\
\hline Bayanga & 2 & $0.28 \%$ & - & - & - & - & 716 \\
\hline Bayabas & 1 & $0.03 \%$ & 4 & $0.12 \%$ & - & - & 3,441 \\
\hline Balubal & 1 & $0.13 \%$ & 2 & $0.26 \%$ & - & - & 779 \\
\hline Mambuaya & 1 & $0.15 \%$ & - & - & - & - & 683 \\
\hline Lapasan & - & - & 1 & $0.01 \%$ & - & - & 10,513 \\
\hline Barangay 24 & - & - & - & - & 139 & $51.87 \%$ & 268 \\
\hline Barangay 23 & - & - & - & - & 85 & $37.61 \%$ & 226 \\
\hline Barangay 20 & - & - & - & - & 11 & $32.35 \%$ & 34 \\
\hline Barangay 25 & - & - & - & - & 9 & $2.69 \%$ & 335 \\
\hline Total & 2,981 & $2.19 \%$ & 6,162 & $4.52 \%$ & 3,998 & $2.93 \%$ & 136,396 \\
\hline
\end{tabular}




\section{Appendix B: Complete list of fields in the 2010 Census of Population and Housing}

\begin{tabular}{ll}
\hline Code & Description \\
\hline reg & Region code \\
prv & Provincial code \\
prrcd & Highly urbanized city code \\
mun & Municipal code \\
bgy & Barangay code \\
husn & Housing unit sequence number \\
hsn & Household sequence number \\
lno & Line number \\
rel & Relationship to household head \\
sex & Sex \\
age & Age \\
breg & Birth registration status \\
ms & Marital status \\
rlgn & Religion \\
cit & Citizenship \\
eth & Ethnicity \\
dis & Disability \\
dsee & Functional difficulty in seeing \\
dhrg & Functional difficulty in hearing \\
dmob & Functional difficulty in walking/climbing \\
dmem & Functional difficulty in remembering or concentrating \\
dslf & Functional difficulty in self-caring \\
dcom & Functional difficulty in communicating \\
r5yr & Residence 5 years ago \\
hgc & Highest academic grade completed \\
ofw & Overseas foreign worker \\
type & Housing type \\
roof & Type of roofing material \\
wall & Type of outer wall material \\
repr & State of repair \\
yrbt & Year built \\
area & Floor area \\
tnur & Tenure status \\
huind & First household in the housing unit \\
\hline &
\end{tabular}


